ARTICLE

https://doi.org/10.1038/s414.67-021-22864-z

\title{
Degradation mechanism of hybrid tin-based perovskite solar cells and the critical role of tin (IV) iodide
}

Luis Lanzetta (1) 1, Thomas Webb (1) 1,3, Nourdine Zibouche ${ }^{2,3}$, Xinxing Liang ${ }^{1}$, Dong Ding ${ }^{1}$, Ganghong Min? Robert J. E. Westbrook ${ }^{1}$, Benedetta Gaggio', Thomas J. Macdonald (1) ${ }^{1}$, M. Saiful Islam (i) ${ }^{2 \bowtie} \&$

Saif A. Haque (10) ${ }^{1 凶}$

Tin perovskites have emerged as promising alternatives to toxic lead perovskites in nextgeneration photovoltaics, but their poor environmental stability remains an obstacle towards more competitive performances. Therefore, a full understanding of their decomposition processes is needed to address these stability issues. Herein, we elucidate the degradation mechanism of 2D/3D tin perovskite films based on (PEA) 0.2 $_{2}(\mathrm{FA})_{0.8} \mathrm{Snl}_{3}$ (where PEA is phenylethylammonium and $\mathrm{FA}$ is formamidinium). We show that $\mathrm{Snl}_{4}$, a product of the oxygen-induced degradation of tin perovskite, quickly evolves into iodine via the combined action of moisture and oxygen. We identify iodine as a highly aggressive species that can further oxidise the perovskite to more $\mathrm{Snl}_{4}$, establishing a cyclic degradation mechanism. Perovskite stability is then observed to strongly depend on the hole transport layer chosen as the substrate, which is exploited to tackle film degradation. These key insights will enable the future design and optimisation of stable tin-based perovskite optoelectronics.

\footnotetext{
${ }^{1}$ Department of Chemistry and Centre for Processable Electronics, Molecular Sciences Research Hub, Imperial College London, London, UK. ${ }^{2}$ Department of Chemistry, University of Bath, Bath, UK. ${ }^{3}$ These authors contributed equally: Thomas Webb, Nourdine Zibouche. ${ }^{\circledR}$ email: m.s.islam@bath.ac.uk; s.a. haque@imperial.ac.uk
} 
ybrid lead halide perovskites remain at the forefront of research activity on next-generation solar cells. Power conversion efficiencies (PCEs) for $\mathrm{APbI}_{3}$ perovskites (where A is typically $\mathrm{CH}_{3} \mathrm{NH}_{3}{ }^{+} / \mathrm{MA}^{+}, \mathrm{CH}_{3}\left(\mathrm{NH}_{2}\right)_{2}{ }^{+} / \mathrm{FA}^{+}$and/or $\mathrm{Cs}^{+}$) have evolved from $3.8 \%$ to $25.5 \%$ within the last decade, surpassing well-established solar cells based on polycrystalline silicon and CuInGaSe ${ }_{2}{ }^{1,2}$. Their outstanding performance is due to their favourable properties such as high carrier diffusion lengths, broad absorption in the visible and near infra-red, and low density of trap states ${ }^{3-9}$.

However, the widespread commercial scaleup of $\mathrm{Pb}$ perovskite devices raises concerns in relation to potential health and environmental hazards that their $\mathrm{Pb}$ content may cause. As such, this makes the development of $\mathrm{Pb}$-free and environmentally friendly perovskite alternatives a high priority. In order to mitigate the toxicity of $\mathrm{Pb}$-halide perovskites but simultaneously retain their favourable photovoltaic properties, $\mathrm{Pb}^{2+}$ can be replaced by lowertoxicity cations with similar outer shell electron configurations, such as $\mathrm{Sn}^{2+}, \mathrm{Ge}^{2+}, \mathrm{Bi}^{3+}$ or $\mathrm{Sb}^{3+10-15}$. Among these options, Sn halide perovskites have emerged as the most promising alternative ${ }^{16-29}$, exhibiting significantly lower bioavailability compared to $\mathrm{Pb}$-based perovskites $^{30}$ and delivering the highest PCEs among Pb-free perovskite solar cells since devices based on $\mathrm{CH}_{3} \mathrm{NH}_{3} \mathrm{SnI}_{3-x} \mathrm{Br}_{x}$ were reported in $2014^{10,11}$. Interest in these materials also arises from their superior semiconductor properties compared to their $\mathrm{Pb}$ analogues, such as broader absorption range, nearly-ideal bandgaps $(\sim 1.3 \mathrm{eV})$ and higher charge carrier mobilities ${ }^{31,32}$.

With record PCEs surpassing $13 \%{ }^{33}$, Sn-based perovskite solar cells have steadily become more competitive due to intensive research efforts. However, the device performance of tin perovskite solar cells has advanced at a slower pace relative to their $\mathrm{Pb}$ counterparts, mainly due to their poorer stability under ambient environmental conditions. Such stability issues with these materials relate mainly to the facile oxidation of $\mathrm{Sn}^{2+}$ to $\mathrm{Sn}^{4+}$, which is also known to introduce p-type self-doping in the perovskite $^{34}$. This in turn leads to high rates of monomolecular electron-hole recombination and therefore poor solar cell performance ${ }^{35}$. A number of strategies have been explored to address these issues, which include the use of $\mathrm{SnX}_{2}$ additives to mitigate self-doping ${ }^{36,37}$, as well as the introduction of inherently

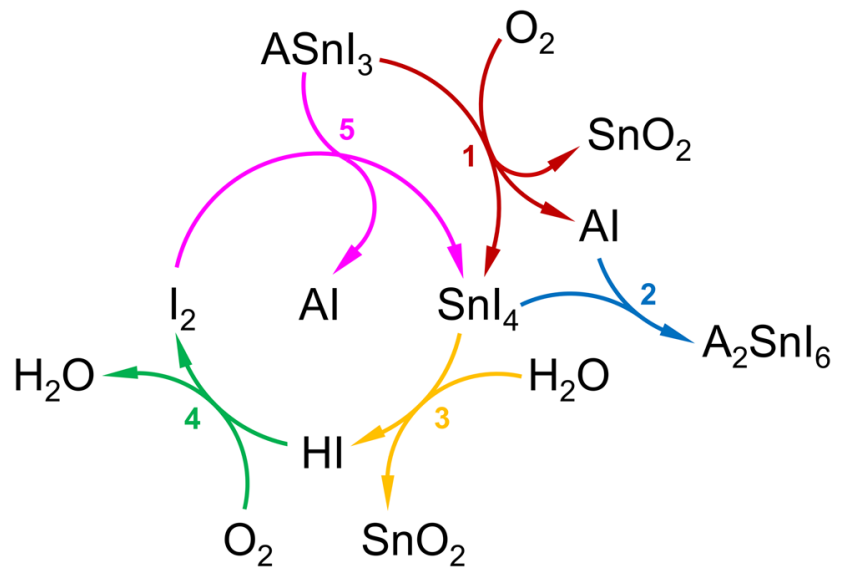

Fig. 1 Proposed cyclic degradation mechanism of a tin iodide perovskite under ambient air exposure. Unless stated otherwise, ' $A$ ' refers to the organic cations chosen for the preparation of the hybrid tin perovskite ( $20 \%$ PEA and $80 \%$ FA in the present work). Reaction 1: oxidation of perovskite by $\mathrm{O}_{2}$ and $\mathrm{Snl}_{4}$ formation; Reaction 2: solid-state formation of $\mathrm{A}_{2} \mathrm{Snl}_{6}$ from $\mathrm{Snl}_{4}$ and $\mathrm{Al}$, where A $\equiv \mathrm{FA}$. Reaction 3: hydrolysis of $\mathrm{Snl}_{4}$ by $\mathrm{H}_{2} \mathrm{O}$ and $\mathrm{HI}$ formation; Reaction 4: oxidation of $\mathrm{HI}$ by $\mathrm{O}_{2}$ and $\mathrm{I}_{2}$ formation; Reaction 5: oxidation of perovskite by $\mathrm{I}_{2}$ and $\mathrm{Snl}_{4}$ formation. more stable low-dimensional phases ${ }^{38-46}$. However, these approaches do not completely solve the problem and therefore a full elucidation of the decomposition pathways of $\mathrm{Sn}$ perovskites is needed to address the stability bottleneck more effectively.

To date, reports describing the degradation mechanism of Sn perovskites remain limited, in contrast with $\mathrm{Pb}$-based analogues ${ }^{47-53}$. For example, some studies have shown that $\mathrm{ASnX}_{3}\left(\mathrm{~A}=\mathrm{Cs}^{+}, \mathrm{MA}^{+}\right.$or $\left.\mathrm{FA}^{+} ; \mathrm{X}=\mathrm{I}^{-}, \mathrm{Br}^{-}\right)$can decompose in air to form $\mathrm{A}_{2} \mathrm{SnX}_{6}$ (vacancy-ordered double perovskite ${ }^{54}$ ) and $\mathrm{SnO}_{2}{ }^{31,55-57}$, while others revealed that $\mathrm{FASnI}_{3}$ and (PEA) $)_{2} \mathrm{SnI}_{4}$ (where PEA refers to phenylethylammonium) degrade in the presence of oxygen to $\mathrm{SnI}_{4}, \mathrm{SnO}_{2}$ and FAI/PEAI ${ }^{58,59}$. Whilst these findings provide plausible air-mediated decomposition routes of Sn-based perovskites, a more detailed understanding of the degradation mechanism as well as knowledge of inconspicuous reaction pathways is required. For example, it is reasonable to suppose that $\mathrm{SnI}_{4}$ can participate in further degradation reactions of $\mathrm{ASnI}_{3}$ on account of its high reactivity with water and oxygen relative to FAI, $\mathrm{SnO}_{2}$ and $\mathrm{A}_{2} \mathrm{SnI}_{6}{ }^{11,60-65}$. Therefore, a more indepth understanding of the role of $\mathrm{SnI}_{4}$ in tin perovskite degradation is necessary.

In this paper, we report on the degradation mechanism of $\mathrm{ASnI}_{3}$ perovskites (where A represents 20\% PEA and 80\% FA) under ambient environmental conditions using a combination of diffraction, spectroscopy and ab initio simulation techniques. Herein, we identify $\mathrm{SnI}_{4}$ as a major contributor to the degradation process and therefore to the instability of such perovskites. Specifically, $\mathrm{SnI}_{4}$ is a direct product of the decomposition of $2 \mathrm{D} / 3 \mathrm{D}$ $(\mathrm{PEA})_{0.2}(\mathrm{FA})_{0.8} \mathrm{SnI}_{3}$ under ambient air ${ }^{58,59}$. We go on to explore the impact of $\mathrm{SnI}_{4}$ on the optoelectronic properties, solar cell performance and stability of (PEA $)_{0.2}(\mathrm{FA})_{0.8} \mathrm{SnI}_{3}$ films. We show that the presence of $\mathrm{SnI}_{4}$ leads to enhanced non-radiative recombination and poorer device $\mathrm{PCE}$, which is due to high free hole density caused by the introduced $\mathrm{Sn}^{4+}$ states. Crucially, we observe that $\mathrm{SnI}_{4}$-richer perovskite films degrade faster under ambient conditions, suggesting that $\mathrm{SnI}_{4}$ accelerates the decomposition of $\mathrm{Sn}$-based perovskites upon exposure to ambient air.

We then investigate the role of $\mathrm{SnI}_{4}$ in the degradation mechanism of $(\mathrm{PEA})_{0.2}(\mathrm{FA})_{0.8} \mathrm{SnI}_{3}$ films and demonstrate that $\mathrm{SnI}_{4}$ in the film readily evolves to form $\mathrm{I}_{2}$ via a two-step process, namely, (i) the hydrolysis reaction of $\mathrm{SnI}_{4}$ with $\mathrm{H}_{2} \mathrm{O}$ to give $\mathrm{HI}$ and (ii) the oxidation of $\mathrm{HI}$ by $\mathrm{O}_{2}$ to form $\mathrm{I}_{2}$. Interestingly, the perovskite is found to rapidly degrade when exposed to $I_{2}$ resulting in the formation of more $\mathrm{SnI}_{4}$, thus establishing a cyclic degradation mechanism shown schematically in Fig. 1.

Finally, we find that the stability of $(\mathrm{PEA})_{0.2}(\mathrm{FA})_{0.8} \mathrm{SnI}_{3}$ perovskite films are highly dependent on the hole transport layer chosen as a substrate (i.e., $\mathrm{NiO}_{x}, \mathrm{CuSCN}$ and PEDOT:PSS). We observe an improvement in perovskite film stability as the hole withdrawal ability of the bottom layer is increased. We suggest that this process chemically reduces the perovskite film, mitigating the high sensitivity of the $\mathrm{Sn}$-based perovskite to both exogenous and endogenous oxidising species $\left(\mathrm{O}_{2}\right.$ and $\left.\mathrm{I}_{2}\right)$. Thus, we expect the implementation of highly efficient hole acceptors to provide a pathway towards more stable tin-based perovskite optoelectronics.

\section{Results}

Degradation in air. As can be seen in Fig. 1, $\mathrm{SnI}_{4}$ plays a pivotal role in the degradation of tin iodide perovskites. As such, we first identify the presence of this species as a degradation product of $2 \mathrm{D} / 3 \mathrm{D} \quad(\mathrm{PEA})_{0.2}(\mathrm{FA})_{0.8} \mathrm{SnI}_{3}$ thin films comparable to those employed in state-of-art solar cells ${ }^{39-42,44}$. Unless specified otherwise, all degradation experiments reported herein were carried out by exposing samples to ambient air (relative humidity, 

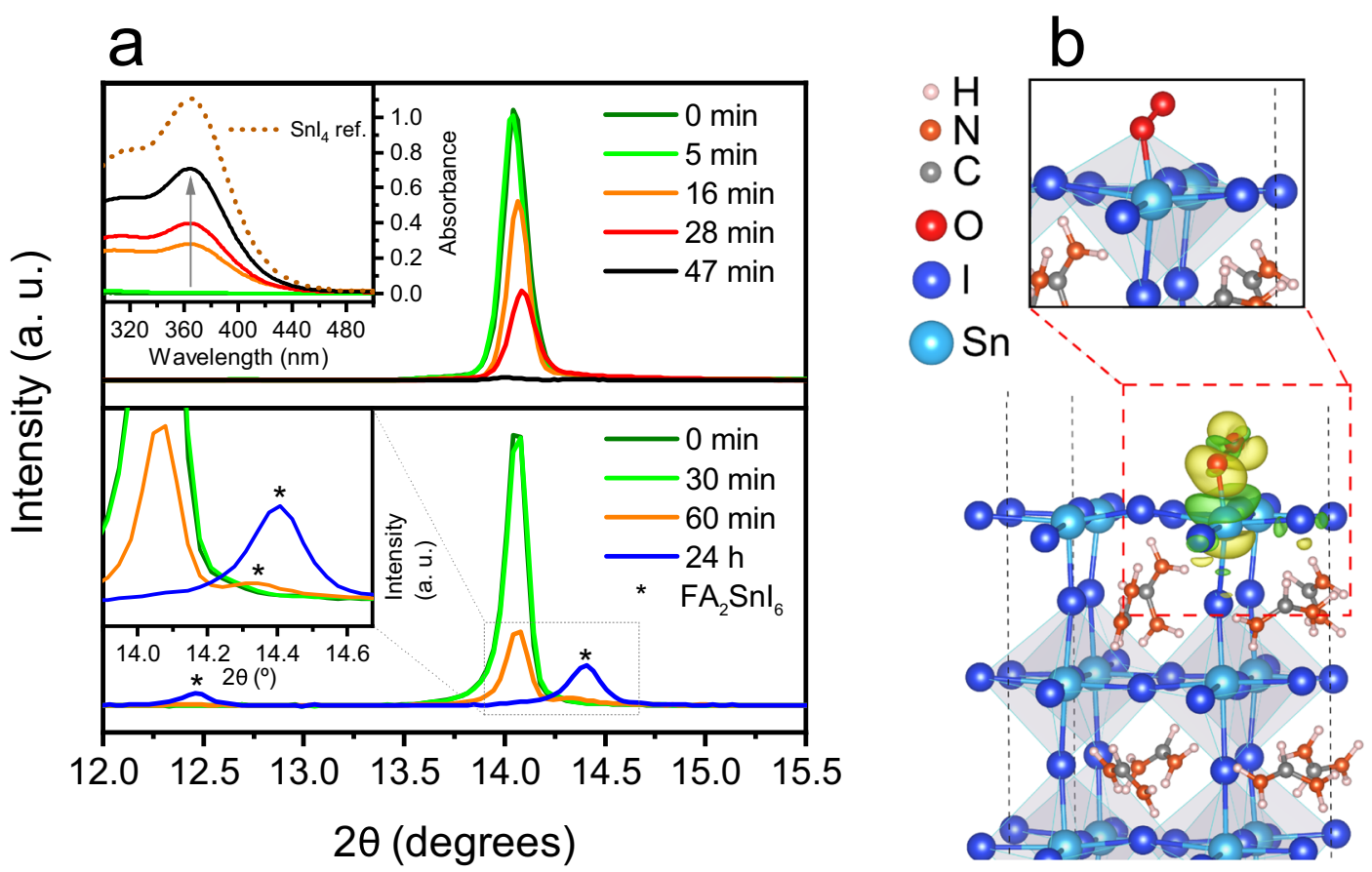

Fig. 2 Degradation of Sn perovskite under ambient air. a Time evolution of the (100) XRD reflection of (PEA) ${ }_{0.2}(\mathrm{FA})_{0.8} \mathrm{Snl}_{3}$ films exposed to ambient air at $100{ }^{\circ} \mathrm{C}$ (top; inset: absorbance spectra of $\mathrm{Snl}_{4}$ dissolved in $3 \mathrm{~mL}$ of toluene after its sublimation from the heated film and capture in a Petri dish during different times) and room temperature (bottom; inset: magnification of peaks corresponding to $60 \mathrm{~min}$ and $24 \mathrm{~h}$ ). Peaks labelled with * correspond to $\mathrm{FA}_{2} \mathrm{Snl}_{6}$. $\mathbf{b}$ Adsorption of an $\mathrm{O}_{2}$ molecule on a (001) surface of $\mathrm{FASnl}_{3}$ perovskite and charge density difference, which highlights bond formation between $\mathrm{O}$ and $\mathrm{Sn}$ atoms (from DFT simulations). Yellow and green charge densities refer to electron accumulation and depletion respectively (with an isosurface value of $\left.0.006 \AA^{-3}\right)$.

$\mathrm{RH}=38.0 \pm 7.5 \%$; temperature, $\left.\mathrm{T}=22.9 \pm 0.9^{\circ} \mathrm{C}\right)$, consistent with normal working conditions. Figure $2 \mathrm{a}$ shows the time evolution of the (100) reflection (orthorhombic system, Amm2 space group; full pattern in Supplementary Fig. 5a) obtained from the $\mathrm{X}$-ray diffraction (XRD) patterns of $(\mathrm{PEA})_{0.2}(\mathrm{FA})_{0.8} \mathrm{SnI}_{3}$ films aged at $100^{\circ} \mathrm{C}$ (Fig. 2a, top) and room temperature (Fig. 2a, bottom).

Tin perovskite films degraded under ambient conditions whilst subjected to $100{ }^{\circ} \mathrm{C}$ heating show a rapid drop in the (100) reflection as they evolve in appearance from black/brown to transparent. This observation is consistent with the disruption of the perovskite crystalline structure due to the oxidative effect of atmospheric oxygen. Such degradation results in the formation of $\mathrm{SnI}_{4}$, which rapidly sublimes under heating. Evidence for the sublimation of $\mathrm{SnI}_{4}$ was obtained by covering the perovskite films with a glass Petri dish during the experiment and immediately extracting the captured products with toluene. The UV-Visible spectra of the captured product (Fig. 2a, top (inset)) clearly indicate the presence of $\mathrm{SnI}_{4}$ as a degradation product. We, therefore, propose Reaction 1 as the first step of Sn perovskite degradation in air, in good agreement with previous reports ${ }^{58,59}$ :

$$
2 \mathrm{ASnI}_{3}+\mathrm{O}_{2} \rightarrow \mathrm{SnI}_{4}+\mathrm{SnO}_{2}+2 \mathrm{AI}
$$

To further complement the experimentally proposed degradation pathways of the Sn perovskite film, we have examined the energetics of Reaction 1 for $\mathrm{FASnI}_{3}$ using density functional theory (DFT) methods. We note that the FA perovskite system was simulated, rather than including PEA, due to the lack of precise experimental crystal structural data for PEA/FA systems similar to the $(\mathrm{PEA})_{0.2}(\mathrm{FA})_{0.8} \mathrm{SnI}_{3}$ precursor ratio as a reliable starting point and to allow a more focused approach on deriving trends of the reaction and surface properties. The reaction energy is calculated as the difference between the products and the reactants (in which a negative value indicates a favourable exothermic reaction). Details of the simulations and procedures, which have been applied recently to tin halide perovskites ${ }^{66,67}$, are provided in the Methods section. We calculate a highly favourable energy $(-3.46 \mathrm{eV})$ for Reaction 1 , which indicates that the perovskite film indeed degrades in the presence of oxygen as the initial step to form FAI, $\mathrm{SnO}_{2}$, and $\mathrm{SnI}_{4}$ in accord with the experimentally observed reaction products.

To examine the microscopic mechanisms of this reaction with oxygen, we also simulated the adsorption of an $\mathrm{O}_{2}$ molecule on the $\mathrm{FASnI}_{3}$ perovskite surface. We examined three possible adsorption configurations of an $\mathrm{O}_{2}$ molecule on the (001) surface with FA/I and Sn/I terminations. We focused on the (001) surface as it has been shown to be one of the most stable and most extensively studied halide perovskite surfaces ${ }^{68,69}$. In the case of FA/I termination, the $\mathrm{O}_{2}$ molecule remains at a certain distance from the surface after relaxation independent of the initial configuration showing no interaction with surface species, which indicates that adsorption does not take place (as shown in Supplementary Fig. 22). For the Sn/I terminated surface, the most stable adsorption structure after relaxation is shown in Fig. 2b, which corresponds to the initial configuration of $\mathrm{O}_{2}$ located right above an $\mathrm{Sn}$ atom (for additional views, see Supplementary Fig. 18b). It is clear that one of the oxygen atoms of the $\mathrm{O}_{2}$ molecule forms a chemical bond with the $\mathrm{Sn}$ atom at the $\mathrm{Sn} / \mathrm{I}$ terminated surface, as shown by the charge density difference in Fig. $2 b$.

Regarding the thermodynamics of adsorption on the surface, we have calculated an adsorption energy of $0.7 \mathrm{eV}$. The $\mathrm{Sn}-\mathrm{O}$ bond length is found to be $2.31 \AA$, which is close to the experimental $\mathrm{Sn}-\mathrm{O}$ bond length in $\mathrm{SnO}_{2}\left(\sim 2.1 \AA^{70}\right)$. We also found that the $\mathrm{O}-\mathrm{O}$ distance is stretched by over $0.1 \AA$ beyond the bond length of the $\mathrm{O}_{2}$ molecule; this elongation suggests that the $\mathrm{O}_{2}$ molecule is likely to be dissociated on the surface and may subsequently participate in the formation of $\mathrm{SnO}_{2}$ (which is a phase detected in our samples via X-ray photoelectron spectroscopy (XPS); Supplementary Fig. 7 and Supplementary Table 1). 
Our simulation results are therefore consistent with the experimentally proposed Reaction 1 and provide additional atomistic insights into the reaction mechanism of the initial stage in the oxidation of the tin perovskite.

The XRD data in Fig. 2a (bottom panel) show that in the film degraded at room temperature the (100) peak intensity also decreases during the course of an hour as a result of ambient air mediated degradation (relative signal loss vs time: $0 \%$ at $0 \mathrm{~min}$, $3 \%$ at $30 \mathrm{~min}, 73 \%$ at $60 \mathrm{~min}$; see Supplementary Fig. 1a). In addition, we observe the appearance of a small diffraction peak at $2 \theta \sim 14.4^{\circ}$ (see Fig. 2a, bottom (inset), $60 \mathrm{~min}$ ), which we attribute to the vacancy-ordered double perovskite variant $\mathrm{FA}_{2} \mathrm{SnI}_{6}{ }^{71}$ (see a full pattern after $24 \mathrm{~h}$ of exposure to ambient air in Supplementary Fig. 1b). However, the emergence of this phase appears to be delayed as compared to perovskite degradation (12\% rise of $\mathrm{FA}_{2} \mathrm{SnI}_{6}$ peak vs. $73 \%$ drop of (PEA) $)_{0.2}(\mathrm{FA})_{0.8} \mathrm{SnI}_{3}$ peak after 60 min; Supplementary Fig. 1a). This suggests that degradation products formed via Reaction 1 gradually accumulate in the film for a prolonged time ( $30-60 \mathrm{~min})$ before triggering the solidstate process between $\mathrm{SnI}_{4}$ and FAI to form $\mathrm{FA}_{2} \mathrm{SnI}_{6}$ (Reaction 2) 71,72 :

$$
\mathrm{SnI}_{4}+2 \mathrm{AI} \rightarrow \mathrm{A}_{2} \mathrm{SnI}_{6}
$$

Taken together, the data in Fig. 2 suggest that the presence of $\mathrm{FA}_{2} \mathrm{SnI}_{6}$ in the film only occurs after substantial perovskite degradation and therefore the early interaction between this phase and $(\mathrm{PEA})_{0.2}(\mathrm{FA})_{0.8} \mathrm{SnI}_{3}$ is unlikely. In contrast, it is evident that $\mathrm{SnI}_{4}, \mathrm{SnO}_{2}, \mathrm{FAI}$ and PEAI coexist with the tin perovskite in the film during the initial stages of the material decomposition. DFT simulations indicate a very small energy $(-0.21 \mathrm{eV})$ for Reaction 2 involving $\mathrm{SnI}_{4}$ interacting with FAI to form the $\mathrm{FA}_{2} \mathrm{SnI}_{6}$ phase, which is consistent with the slower formation of this phase. Upon degrading the sample under heating, we also note that the eventual formation of $\mathrm{FA}_{2} \mathrm{SnI}_{6}$ is impeded due to the rapid sublimation of $\mathrm{SnI}_{4}$.

Optoelectronic and stability effects of tin (IV) iodide. Next, we examine the effect of $\mathrm{SnI}_{4}$ on the optoelectronic properties, device performance and ambient stability of $(\mathrm{PEA})_{0.2}(\mathrm{FA})_{0.8} \mathrm{SnI}_{3}$ films. For this, the $\mathrm{SnI}_{4}$ content in the perovskite films was varied by tuning the $\mathrm{SnI}_{4}$ concentration in the perovskite precursor solution by both thermally purifying the control (commercially sourced) $\mathrm{SnI}_{2}$ precursor to minimise its $\mathrm{SnI}_{4}$ impurities and by replacing 2 mol\% control $\mathrm{SnI}_{2}$ by equimolar amounts of $\mathrm{SnI}_{4}$. We note that details of precursor purification (experimental setup and conditions, Supplementary Fig. 2; thermogravimetric analysis (TGA), Supplementary Fig. 3a; $\mathrm{SnI}_{4}$ identification and quantification, Supplementary Fig. 4), the effect of control/purified $\mathrm{SnI}_{2}$ on the perovskite film structure (XRD, Supplementary Fig. 5), morphology (scanning electron microscopy (SEM), Supplementary Fig. 6), and composition (XPS; Supplementary Fig. 7 and Supplementary Table 1) are provided in the Supplementary Information.

Figure 3a shows the UV-Visible absorption characteristics of three perovskite films: sample (A), film made with purified commercial $\mathrm{SnI}_{2}$ (0.06\% $\mathrm{SnI}_{4}$ content); sample (B), film made with as-received commercial $\mathrm{SnI}_{2}\left(0.65 \% \mathrm{SnI}_{4}\right.$ content $)$ and sample (C), film made with commercial $\mathrm{SnI}_{2}$ and $2 \mathrm{~mol} \% \mathrm{SnI}_{4}$ (3.95\% $\mathrm{SnI}_{4}$ content). We note that XPS measurements confirm an increase in $\mathrm{Sn}^{4+}$ content in films processed with $\mathrm{SnI}_{4}$-richer $\mathrm{SnI}_{2}$ precursors (Supplementary Fig. 7). Moreover, it is apparent from Fig. 3a that the optical bandgaps of samples (A) and (B) are found to be $\sim 1.32 \mathrm{eV}$, while that of sample (C) is $1.35 \mathrm{eV}$ (Tauc plots provided in Supplementary Fig. 8). It is possible that the larger bandgap observed in sample (C) may originate from its more pronounced p-type character; a higher $\mathrm{SnI}_{4}$ content introduces more $\mathrm{Sn}^{4+}$ states in the perovskite, resulting in a hole-richer valence band and therefore causing band-to-band electron transitions to occur at higher energies.

Figure $3 \mathrm{~b}$ presents time-resolved photoluminescence (PL) decays for samples (A), (B) and (C). It is apparent that longer fluorescence lifetimes are observed in films made with less exogenous $\mathrm{SnI}_{4}$ (sample A: $\tau=5.49 \mathrm{~ns}>$ sample B: $\tau=2.09 \mathrm{~ns}>$ sample $C: \tau=0.60 \mathrm{~ns})$. We attribute the increase in emission lifetime in sample $\mathrm{A}$ as compared to samples $\mathrm{B}$ and $\mathrm{C}$ to a reduction in non-radiative monomolecular recombination rates that arise from the fewer $\mathrm{Sn}^{4+}$ states that are incorporated into the perovskite structure; this being in good agreement with our XPS data (Supplementary Fig. 7 and Supplementary Table 1) and previous work ${ }^{73}$. Taken together, the data presented in Fig. 3a, b highlight the detrimental impact of $\mathrm{SnI}_{4}$ on the photophysical properties of Sn-based perovskites. It is pertinent to note that purifying the precursor (via sublimation) prior to film processing results in an improvement in the optoelectronic properties of the material.

We next consider the influence of $\mathrm{SnI}_{4}$ on device performance. Figure $3 c$ shows current density-voltage $(J-V)$ curves of $\mathrm{Sn}$ perovskite solar cells based on a typical inverted architecture (ITO/PEDOT:PSS/(PEA) $)_{0.2}(\mathrm{FA})_{0.8} \mathrm{SnI}_{3} / \mathrm{PC}_{60} \mathrm{BM} / \mathrm{BCP} / \mathrm{Ag}$; see inset). Photovoltaic figures of merit of our devices are summarised in Supplementary Fig. 9 (box plots) and Supplementary Table 2. Solar cells made with the purified $\mathrm{SnI}_{2}$ attain high efficiencies (5.23\%) compared to previous reports based on similar 2D/3D absorbers $^{39,74}$. The high open-circuit voltage $\left(V_{o c}\right)(0.61 \mathrm{~V})$ and fill factor $(71 \%)$ achieved indicate low trap-mediated recombination and balanced charge transport. However, the relatively low shortcircuit current density $\left(J_{s c}\right)$ is possibly caused by charge losses at perovskite/PEDOT:PSS and/or perovskite/ $\mathrm{PC}_{60} \mathrm{BM}$ interfaces. In contrast, it is evident from $\mathrm{J}-\mathrm{V}$ data in Fig. $3 \mathrm{c}$ that increasing the $\mathrm{SnI}_{4}$ content in the perovskite layer leads to a significant drop in the PCE $(5.23 \%>1.73 \%)$ due to a drop in $V_{o c}(0.61 \mathrm{~V}>0.55 \mathrm{~V})$ and $J_{s c}$ $\left(12.00 \mathrm{~mA} / \mathrm{cm}^{2}>4.61 \mathrm{~mA} / \mathrm{cm}^{2}\right)$; this is consistent with increased carrier recombination and lower carrier mobility as $\mathrm{Sn}^{4+}$ doping is introduced $^{75,76}$.

Next, we consider the effect of $\mathrm{SnI}_{4}$ on the stability of $(\mathrm{PEA})_{0.2}(\mathrm{FA})_{0.8} \mathrm{SnI}_{3}$ films. Contour graphs showing normalised absorbance of samples (A), (B) and (C) as a function of time and wavelength are shown in Supplementary Fig. 10. These measurements indicate a drop in absorbance across the spectrum but more notably around 660 and $870 \mathrm{~nm}$, close to the energies of the two main allowed optical transitions in these materials ${ }^{77}$. Normalised absorbance decays at $660 \mathrm{~nm}$ are plotted in Fig. 3d for comparison. The data presented in Fig. $3 \mathrm{~d}$ show that the presence of $\mathrm{SnI}_{4}$ significantly increases the rate of degradation of $(\mathrm{PEA})_{0.2}(\mathrm{FA})_{0.8} \mathrm{SnI}_{3}$ films (stability: sample $(\mathrm{A})>$ sample $(\mathrm{B})>$ sample $(\mathrm{C})$ ).

Evolution of tin (IV) iodide to iodine. So far, we have shown that: (i) $\mathrm{SnI}_{4}$ is generated as a product of the oxygen-induced degradation of Sn-based perovskite films and (ii) the presence of $\mathrm{SnI}_{4}$ in the film is highly detrimental to the optoelectronic properties, device performance and ambient stability of $(\mathrm{PEA})_{0.2}(\mathrm{FA})_{0.8} \mathrm{SnI}_{3}$ films. Whilst the deterioration of the optoelectronic properties and photovoltaic performance in the material can be attributed to non-radiative recombination caused by $\mathrm{Sn}^{4+}$ dopants, the role of $\mathrm{SnI}_{4}$ in the degradation mechanism and stability of $\mathrm{Sn}$ perovskites remains unclear. It is reasonable to suppose that $\mathrm{SnI}_{4}$ can spontaneously evolve into iodine in the presence of moisture and oxygen ${ }^{11,60-65}$ as indicated in Fig. 1. This is in agreement with empirical thermodynamic data ${ }^{78,79}$ 

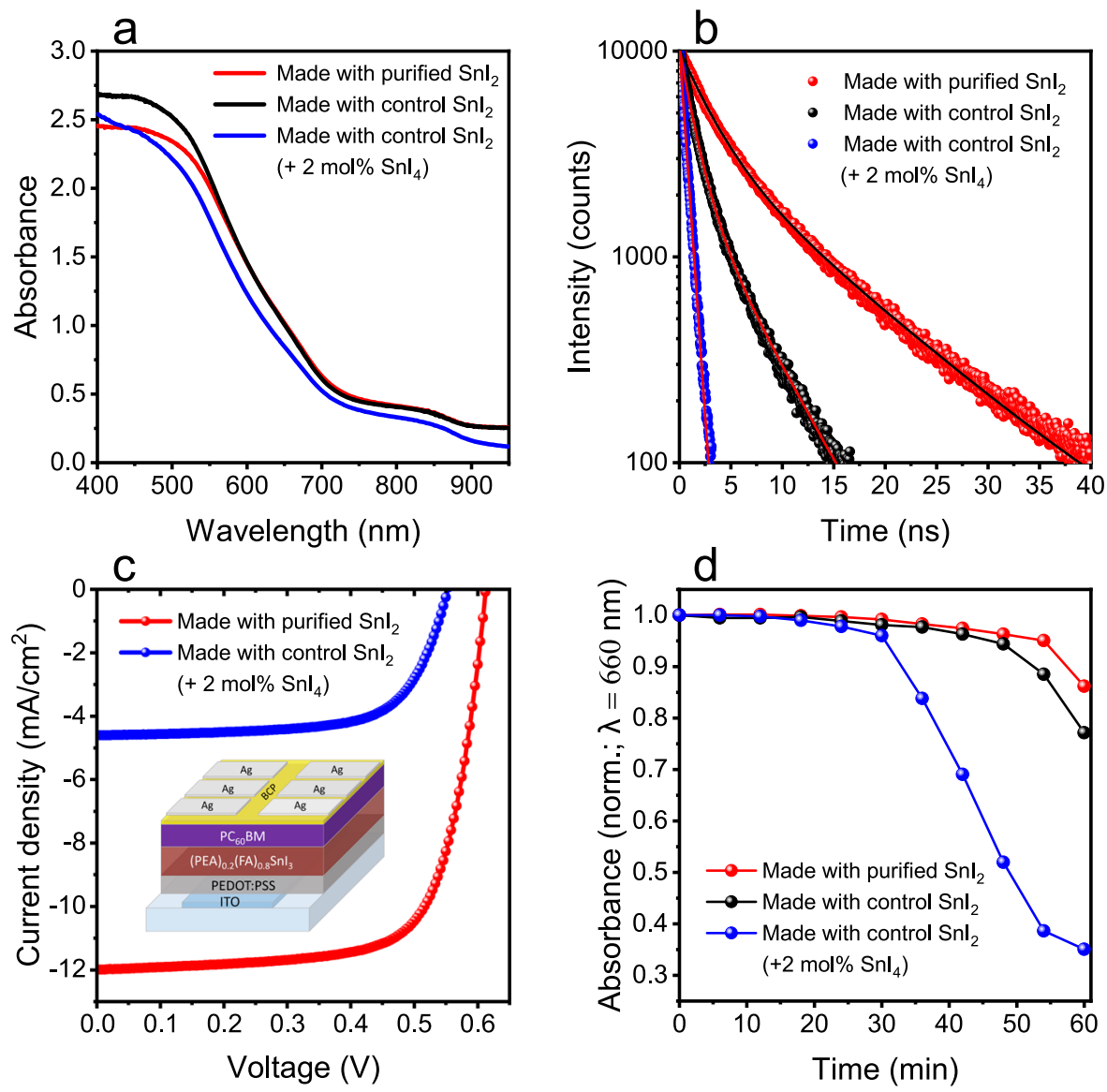

Fig. 3 Effect of tin (IV) iodide on Sn perovskite optical properties, solar cell performance and stability. a UV-Visible spectra of glass/

$(\mathrm{PEA})_{0.2}(\mathrm{FA})_{0.8} \mathrm{Snl}_{3}$ thin films made with varying $\mathrm{Snl}_{4}$ concentrations. b Time-resolved PL decays of perovskite films acquired at $875 \mathrm{~nm}$ with $404 \mathrm{~nm}$ excitation and their fitting curves. Average $\tau_{f}$ for films are $5.49 \mathrm{~ns}$ (film made with purified $\mathrm{Snl}_{2}$; biexponential decay fit), $2.09 \mathrm{~ns}$ (film made with control $\mathrm{Snl}_{2}$; biexponential decay fit) and $0.60 \mathrm{~ns}$ (film with added $\mathrm{Snl}_{4}$; monoexponential decay fit). c. Current density-voltage (J-V) curves of champion solar cells based on $(\mathrm{PEA})_{0.2}(\mathrm{FA})_{0.8} \mathrm{Snl}_{3}$ made with varying $\mathrm{Snl}_{4}$ concentrations. d. Time evolution of relative absorbance at $660 \mathrm{~nm}$ of perovskite thin films made with varying $\mathrm{Snl}_{4}$ concentrations. Degradation experiments were carried out under dark and ambient air conditions $\left(23^{\circ} \mathrm{C}, 38 \% \mathrm{RH}\right)$.

showing that (i) $\mathrm{SnI}_{4}$ can hydrolyse to form $\mathrm{SnO}_{2}$ and $\mathrm{HI}$ (Gibbs free energy: $\Delta G^{\circ}=-0.60 \mathrm{eV}$ ) and, similarly, (ii) $\mathrm{HI}$ can react with oxygen to give $\mathrm{I}_{2}$ and $\mathrm{H}_{2} \mathrm{O}\left(\Delta G^{\circ}=-2.20 \mathrm{eV}\right)$. To investigate whether these reactions are feasible in the perovskites reported herein, a combination of proton nuclear magnetic resonance $\left({ }^{1} \mathrm{H}-\right.$ NMR) and UV-Visible spectroscopies were used.

First, ${ }^{1} \mathrm{H}$-NMR spectroscopy is used to analyse the interaction of $\mathrm{SnI}_{4}$ with moisture in a $(\mathrm{PEA})_{0.2}(\mathrm{FA})_{0.8} \mathrm{SnI}_{3}$ film degraded under ambient air for $24 \mathrm{~h}$ and dissolved in deuterated DMSO (Fig. 4a). We note that full (downfield) NMR spectra of the solvent, FAI, PEAI, fresh $(\mathrm{PEA})_{0.2}(\mathrm{FA})_{0.8} \mathrm{SnI}_{3}$, aged $(\mathrm{PEA})_{0.2}$ $(\mathrm{FA})_{0.8} \mathrm{SnI}_{3}$ and their peak assignment are provided in Supplementary Fig. 11, indicating that $\mathrm{FA}^{+}$and $\mathrm{PEA}^{+}$do not undergo any structural alterations within the $24 \mathrm{~h}$ degradation period. However, the peak assigned to $\mathrm{H}_{2} \mathrm{O}$ traces is detected at $\sim 3.53$ $\mathrm{ppm}$ in the upfield degraded perovskite spectrum, in contrast with its position at $\sim 3.35 \mathrm{ppm}$ in the reference DMSO- $\mathrm{d}_{6}, \mathrm{FAI}$, PEAI and fresh perovskite spectra (Fig. 4a). The downfield shift in the $\mathrm{H}_{2} \mathrm{O}$ peak is indicative of a decrease in electron density around water protons (de-shielding effect), consistent with the protonation of water (i.e., formation of $\mathrm{H}_{3} \mathrm{O}^{+}$). The acidification of water is consistent with the formation of $\mathrm{HI}$ through the reaction of $\mathrm{SnI}_{4}$ with $\mathrm{H}_{2} \mathrm{O}$, as detailed in Reaction $3^{8,60,61,63-65}$ :

$$
\mathrm{SnI}_{4}+2 \mathrm{H}_{2} \mathrm{O} \rightarrow 4 \mathrm{HI}+\mathrm{SnO}_{2}
$$

It is pertinent to note that $\mathrm{HI}$ can participate in further reactions under ambient conditions due to its highly reactive nature. For example, $\mathrm{HI}$ formed as a result of water-mediated degradation of $\mathrm{CH}_{3} \mathrm{NH}_{3} \mathrm{PbI}_{3}{ }^{80,81}$ has been suggested to evolve in the air to form $\mathrm{I}_{2}{ }^{82}$. As such, a plausible reaction route for $\mathrm{HI}$ oxidation to give $\mathrm{I}_{2}$ and $\mathrm{H}_{2} \mathrm{O}$ is represented in Reaction 4:

$$
4 \mathrm{HI}+\mathrm{O}_{2} \rightarrow 2 \mathrm{I}_{2}+2 \mathrm{H}_{2} \mathrm{O}
$$

Further evidence for Reactions 3 and 4 occuring was obtained from studying the reaction of water with $\mathrm{SnI}_{4}$, followed by exposure to air (Supplementary Fig. 12). Specifically, upon the addition of $\mathrm{SnI}_{4}$ to water, we observe a drop in $\mathrm{pH}$ and the precipitation of a white solid, consistent with the formation of $\mathrm{HI}$ and $\mathrm{SnO}_{2}$, respectively. Moreover, ageing this mixture in air leads to a colour change (from clear to yellow/orange) along with new absorption features that indicate the oxidation of $\mathrm{HI}$ to $\mathrm{I}_{2}$ (see Supplementary Fig. 12). We note that the photoinduced decomposition of $\mathrm{HI}$ into its elements $\left(\mathrm{H}_{2}\right.$ and $\left.\mathrm{I}_{2}\right)$ cannot be excluded, although we expect this path to be less favourable due to thermodynamic limitations ${ }^{83-85}$. Taken together, Reactions 3 and 4 suggest that $\mathrm{SnI}_{4}$ is highly likely to evolve into $\mathrm{I}_{2}$ through the cooperative action of atmospheric $\mathrm{H}_{2} \mathrm{O}$ and $\mathrm{O}_{2}$, with $\mathrm{HI}$ most likely acting as a short-lived, intermediate species. We note that the direct reaction of $\mathrm{SnI}_{4}$ with $\mathrm{O}_{2}$ to form $\mathrm{I}_{2}$ and $\mathrm{SnO}_{2}$ is also a possibility; nonetheless, this process is known to require high 

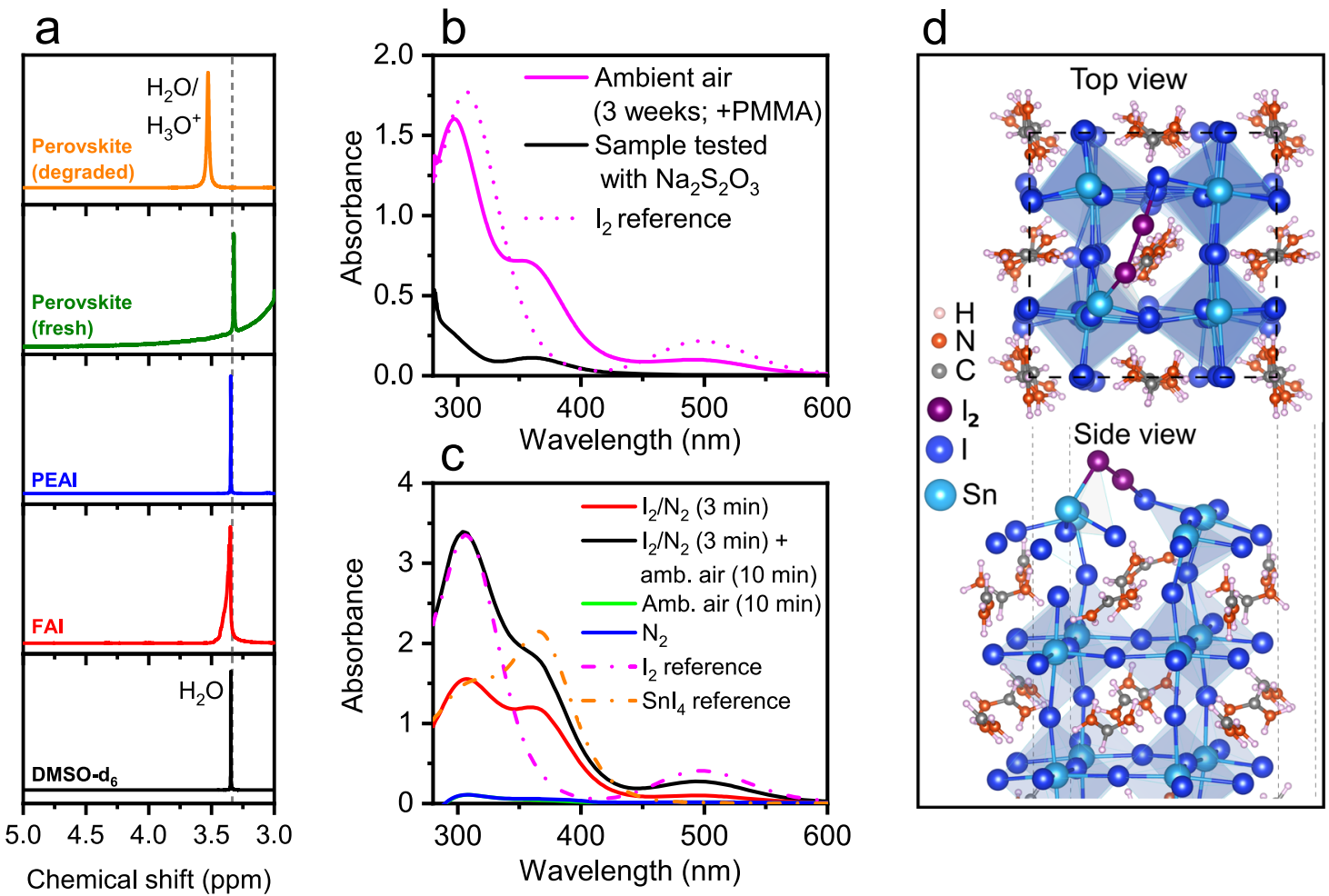

Fig. 4 Evolution of tin (IV) iodide to iodine and Sn perovskite oxidation by iodine. a Upfield ${ }^{1} \mathrm{H}-\mathrm{NMR}$ spectra of DMSO-d $\mathrm{d}_{6}, \mathrm{FAl}, \mathrm{PEAl}$, fresh $(\mathrm{PEA})_{0.2}(\mathrm{FA})_{0.8} \mathrm{Snl}_{3}$ and $(\mathrm{PEA})_{0.2}(\mathrm{FA})_{0.8} \mathrm{Snl}_{3}$ aged for $24 \mathrm{~h}$ in ambient air. $\mathbf{b}$ UV-Visible spectra of degradation products extracted in toluene ( $3 \mathrm{~mL}$ ) from a PMMA-coated (PEA) $)_{0.2}(\mathrm{FA})_{0.8} \mathrm{Snl}_{3}$ thin-film fully aged in ambient air for 3 weeks, the same solution after $\mathrm{Na}_{2} \mathrm{~S}_{2} \mathrm{O}_{3}$ addition and $\mathrm{I}_{2}$ reference solution (dotted line) c UV-Visible spectra of degradation products extracted in toluene $(3 \mathrm{~mL})$ from $(\mathrm{PEA})_{0.2}(\mathrm{FA})_{0.8} \mathrm{Snl}_{3}$ thin films aged under different conditions (indicated in legend) and $\mathrm{Snl}_{4}$ and $\mathrm{I}_{2}$ reference solutions (dashed lines). d Top and side views of the structural arrangement of an adsorbed $\mathrm{I}_{2}$ molecule (purple) on the (001) surface of $\mathrm{FASnl}_{3}$ (from DFT calculations).

temperatures to occur ${ }^{62}$ and therefore we consider it to be much slower relative to Reactions 3 and 4 combined.

In order to verify the evolution of $\mathrm{SnI}_{4}$ into $\mathrm{I}_{2}$ in $(\mathrm{PEA})_{0.2}$ $(\mathrm{FA})_{0.8} \mathrm{SnI}_{3}$ perovskite films under air, we next analyse degraded samples via UV-Visible spectroscopy to detect the halogen. The absorbance spectrum of degradation products extracted via toluene from a film aged in ambient air for 3 weeks is presented in Fig. $4 \mathrm{~b}$. The resulting UV-Visible characteristics in Fig. 4 b show a shoulder at $\sim 360 \mathrm{~nm}$, assigned to $\mathrm{SnI}_{4}$, and two further features at $\sim 300$ and $\sim 500 \mathrm{~nm}$ consistent with the presence of $\mathrm{I}_{2}$ (see $\mathrm{I}_{2}$ reference spectrum, Fig. 4b). The elimination of these two features by testing the solution with $\mathrm{Na}_{2} \mathrm{~S}_{2} \mathrm{O}_{3}$, which is known to reduce $\mathrm{I}_{2}$ to $\mathrm{I}^{-}$, further supports the presence of $\mathrm{I}_{2}$ as a product of the degradation of $\mathrm{SnI}_{4}$. We note that the evolution of $\mathrm{SnI}_{4}$ to $\mathrm{I}_{2}$ is also observed in toluene solutions (Supplementary Fig. 13).

Perovskite oxidation by iodine. The next question that arises relates to whether iodine can directly react with the perovskite and cause further degradation of the material. To investigate this, we exposed fresh (PEA) $)_{0.2}(\mathrm{FA})_{0.8} \mathrm{SnI}_{3}$ films to artificially generated $\mathrm{I}_{2}$ atmospheres for short periods of time ( 350 ppm $\mathrm{I}_{2}, \sim 3$ $\mathrm{min}$ ) and used UV-Visible spectroscopy to study the reaction. Details of the experimental procedure and sample characterisation can be found in 'Methods'. We find that Sn perovskite films exposed to $I_{2}$ vapour result in a dramatic colour change (from black/brown to pale orange, Supplementary Fig. 14) attributed to perovskite degradation. Figure $4 \mathrm{c}$ shows the absorbance spectrum of degradation products extracted in toluene from an $\mathrm{I}_{2}$-exposed film. The absorption peak at $\sim 360 \mathrm{~nm}$ reveals once more the presence of $\mathrm{SnI}_{4}$, confirming that $\mathrm{I}_{2}$ oxidises the $\mathrm{Sn}$ perovskite to
$\mathrm{SnI}_{4}$ (via Reaction 5):

$$
\mathrm{ASnI}_{3}+\mathrm{I}_{2} \rightarrow \mathrm{SnI}_{4}+\mathrm{AI}
$$

DFT calculations find a favourable energy $(-0.61 \mathrm{eV})$ for this reaction (5) involving $\mathrm{I}_{2}$ interacting with $\mathrm{FASnI}_{3}$ to form $\mathrm{SnI}_{4}$ and FAI, which again agrees with experimental observation. To further analyse the detrimental role of $\mathrm{I}_{2}$, we also simulated the absorption of an $\mathrm{I}_{2}$ molecule on the (001) surface of $\mathrm{FASnI}_{3}$ in a similar methodology to the case of $\mathrm{O}_{2}$. Figure $4 \mathrm{~d}$ shows the most stable structure after relaxation on the $\mathrm{Sn} / \mathrm{I}$ terminated surface, which corresponds to $\mathrm{I}_{2}$ above the FA molecular cation (for further views, see Supplementary Fig. 20). The top view in Fig. 4d shows that the $\mathrm{I}_{2}$ molecule forms bridge-like bonds between the $\mathrm{Sn}$ and I atoms at the Sn/I terminated surface. The side view shows that the Sn atom that is bonded with one of the I atoms of the molecule is pulled out of the $\mathrm{SnI}_{2}$ surface, distorting the local regular Sn coordination of the perovskite structure. This suggests that the $\mathrm{I}_{2}$ species reacts with the perovskite crystal and most likely results in the formation of additional $\mathrm{SnI}_{4}$ as proposed experimentally in Reaction 5. When the surface is FA/I terminated, the $\mathrm{I}_{2}$ molecule interacts with the outer iodine atom of the surface and forms a triiodide-like molecular shape, independent of the initial configurations, as shown in Supplementary Fig. 23. Overall, these results show that our simulations are in line with the experimental findings of the cyclic degradation process, as well as providing new mechanistic insights at the atomic level.

Cyclic degradation mechanism of Sn perovskite. Our findings provide a detailed description of the degradation processes in Sn perovskite films under ambient air, as schematically depicted in Fig. 1. The decomposition of the material is triggered by oxygen, 
which oxidises the perovskite to $\mathrm{SnI}_{4}$ (Reaction 1). Next, this degradation product can follow two reaction pathways, namely (i) its solid-state evolution to form a vacancy-ordered Sn(IV) double perovskite (Reaction 2) and, more critically, (ii) its evolution in the presence of moisture and oxygen via, most likely, a HI intermediate to give $\mathrm{I}_{2}$ (Reactions 3 and 4), which we find to be a fast process $(<10 \mathrm{~min}$; Supplementary Note 1$)$. (PEA $)_{0.2}$ (FA) $)_{0.8} \mathrm{SnI}_{3}$ films are found to degrade rapidly $(<3 \mathrm{~min})$ when exposed to $\mathrm{I}_{2}$ at lower concentrations than atmospheric $\mathrm{O}_{2}$ $\left(\sim 0.035 \% \mathrm{I}_{2}<\sim 21 \% \mathrm{O}_{2}\right)$. As can be seen in Fig. $1, \mathrm{SnI}_{4}$ and $\mathrm{I}_{2}$ can interconvert while causing the decomposition of the perovskite. We believe that our mechanistic insights explain why $\mathrm{SnI}_{4}$ impurities in the perovskite precursor lead to greater premature perovskite degradation (Fig. 3d): the presence of exogenous $\mathrm{SnI}_{4}$ in the perovskite may speed up the formation of highly aggressive $\mathrm{I}_{2}$, which in turns leads to the degradation of the perovskite.

In order to obtain further evidence for our degradation mechanism presented in Fig. 1, we investigated the stability of $(\mathrm{PEA})_{0.2}(\mathrm{FA})_{0.8} \mathrm{SnI}_{3}$ films in the presence or absence of agents that

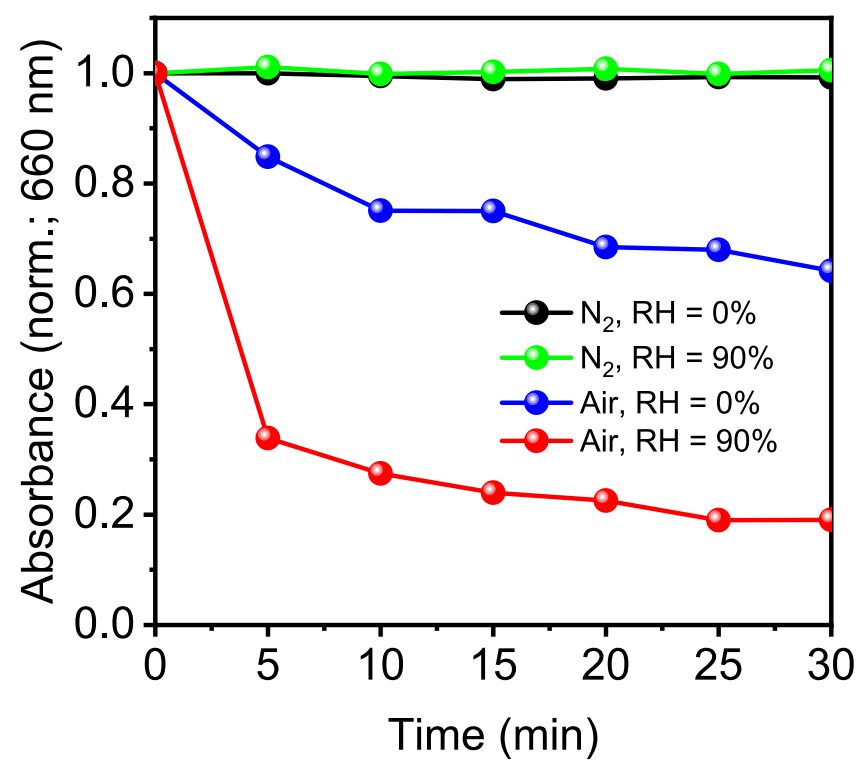

Fig. $5 \mathrm{Sn}$ perovskite degradation tests under dry/moist air/nitrogen flow. Optical degradation of (PEA) $)_{0.2}(\mathrm{FA})_{0.8} \mathrm{Snl}_{3}$ films at $660 \mathrm{~nm}$ upon exposure to a flow of dry $\mathrm{N}_{2}(\mathrm{RH}=0 \%)$, moist $\mathrm{N}_{2}(\mathrm{RH}=90 \%)$, dry air $(\mathrm{RH}=0 \%)$ and moist air $(\mathrm{RH}=90 \%)$.
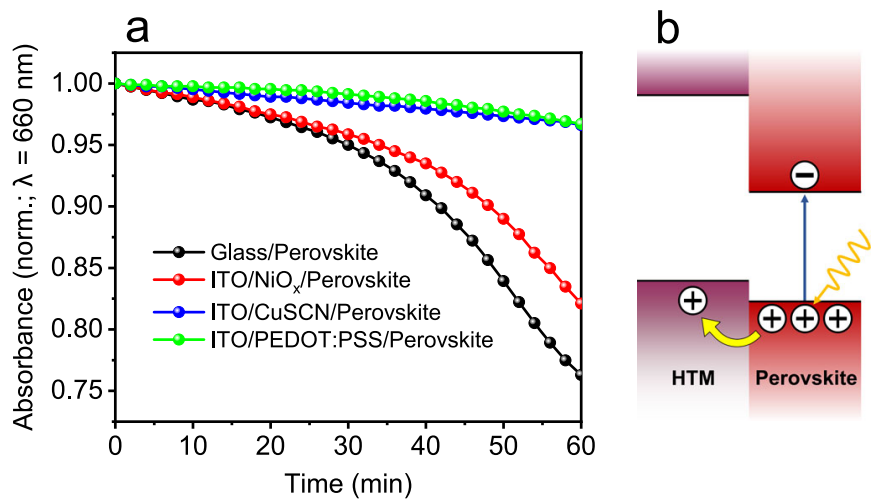

trigger material decomposition, i.e., $\mathrm{O}_{2}$ and $\mathrm{H}_{2} \mathrm{O}$. In these experiments, we exposed the perovskite films to an artificially generated flow of $\mathrm{N}_{2}$ or air under different relative humidity conditions $(\mathrm{RH}=0 \%$ or $\mathrm{RH}=90 \%)$ and tracked their optical degradation at $660 \mathrm{~nm}$ for a period of $30 \mathrm{~min}$ (see Fig. 5). We note that experimental details of these studies are provided in the Methods section. As expected, no degradation is observed when the films are exposed to dry or moist $\mathrm{N}_{2}(\mathrm{RH}=0 \%$ and $\mathrm{RH}=90 \%$ respectively). The presence of $\mathrm{H}_{2} \mathrm{O}$ in the latter may cause hydrolysis of $\mathrm{SnI}_{4}$ impurities in the film to $\mathrm{HI}$ via Reaction 3, but $\mathrm{O}_{2}$ is required for the degradation cycle to progress into $\mathrm{I}_{2}$. Moreover, perovskite films exposed to dry air $(\mathrm{RH}=0 \%)$ show a decay in absorbance that is consistent with the $\mathrm{O}_{2}$-mediated degradation of the material via Reaction 1 . However, when the perovskite film is exposed to moist air $(\mathrm{RH}=90 \%)$ optical degradation becomes much more pronounced, which we attribute to the presence of $\mathrm{H}_{2} \mathrm{O}$ activating the degradation cycle via Reaction 3. As such, these findings further support the proposed degradation mechanism and highlight the importance of avoiding oxygen and moisture to preserve Sn perovskite stability. We anticipate that the use of highly hydrophobic coatings in perovskite optoelectronic devices (e.g., ultrathin interlayers) will dramatically increase material resilience under ambient conditions, in accordance with the findings detailed here.

Stabilisation of Sn perovskite films. We have shown that $\mathrm{Sn}$ perovskite films degrade under the oxidative action of atmospheric $\mathrm{O}_{2}$ and endogenously formed $\mathrm{I}_{2}$. These agents chemically decompose the perovskite, causing the oxidation of $\mathrm{Sn}^{2+}$ to $\mathrm{Sn}^{4+}$ to form $\mathrm{SnI}_{4}$. The details of the mechanism governing the degradation process provided here enable strategies to stabilise the $\mathrm{Sn}$ perovskite. As such, the removal of $\mathrm{SnI}_{4}$ and thus $\mathrm{Sn}^{4+}$ species from the precursor and film may help delay the perovskite decomposition in air. To further minimise the oxidation of $\mathrm{Sn}^{2+}$ to $\mathrm{Sn}^{4+}$, it is also important to consider the impact that other layers in the device (e.g., charge transport layers) may have on perovskite stability.

To this end, we explore the influence of the bottom, hole transport materials (HTM) on the stability of ITO/HTM/ $(\mathrm{PEA})_{0.2}(\mathrm{FA})_{0.8} \mathrm{SnI}_{3}$ samples exposed to air. Specifically, $\mathrm{NiO}_{x}$, CuSCN and PEDOT:PSS were used as HTMs and glass/ $(\mathrm{PEA})_{0.2}(\mathrm{FA})_{0.8} \mathrm{SnI}_{3}$ was employed as a control sample. The samples were exposed to ambient air for $60 \mathrm{~min}$ and UV-Visible spectroscopy was employed to monitor degradation. Figure $6 a$ shows the absorbance at $660 \mathrm{~nm}$ vs. time. We note that normalised UV-Visible absorption graphs vs. wavelength and 
time are presented in Supplementary Fig. 16. From the data presented in Fig. 6a, we observe that the stability of the tin perovskite layer strongly depends on the substrate it is used with. For example, ITO/PEDOT:PSS/perovskite and ITO/CuSCN/ perovskite samples exhibit superior stability, followed by the $\mathrm{ITO} / \mathrm{NiOx} /$ perovskite sample and then glass/perovskite sample.

Next, we discuss the possible origins of this trend. $\mathrm{NiO}_{x}$, CuSCN and PEDOT:PSS have been used as HTMs in highperformance $\mathrm{Sn}$ perovskite solar cells ${ }^{43,44,86}$. We propose that $\mathrm{NiO}_{\mathrm{x}}, \mathrm{CuSCN}$ and PEDOT:PSS can also accept the excess of dark holes inherently found in the Sn-based perovskite valence band that cause their unwanted p-doping (Fig. 6b). It is plausible that this effect may chemically translate as the reduction of $\mathrm{Sn}^{4+}$ states within the depletion region to $\mathrm{Sn}^{2+}$, which would delay the degradation steps described in Fig. 1 and preserve the Sn perovskite structure for longer. To test the overall ability of HTMs to withdraw holes from the perovskite, we measured the steadystate PL spectra of our samples (Fig. 6c). We observe that perovskite emission is reduced in all perovskite/HTM substrates relative to a perovskite/glass control; this is consistent with PL quenching via photoinduced hole transfer.

More direct evidence for hole transfer was obtained via timeresolved PL spectroscopy (Supplementary Fig. 17); faster charge recombination kinetics is observed in all samples containing HTM substrates, indicating efficient hole transfer from the perovskite. Taken together, the data presented in Fig. 6 suggest that the stability of the tin perovskite layer can be enhanced by improving hole transfer at the perovskite/HTM heterojunction. We note that other factors may also influence stability, such as HTM/perovskite interface passivation, chemical reactivity between HTM and perovskite and substrate-dependent point defect formation. A detailed description of the role of these issues is beyond the scope of the current manuscript and will be reported in future work.

\section{Discussion}

Using a combination of diffraction, spectroscopy and ab initio simulation techniques, this study provides a greater understanding of the degradation mechanisms in tin perovskites, which is crucial in addressing their stability issues. The present findings illustrate the important role of $\mathrm{SnI}_{4}$ in the optoelectronic properties, device performance and ambient degradation of tin perovskite films based on 2D/3D (PEA) $0.2(\mathrm{FA})_{0.8} \mathrm{SnI}_{3}$. We reveal that $\mathrm{SnI}_{4}$, both as a precursor impurity and as a perovskite degradation product, can rapidly evolve in ambient air to form $\mathrm{I}_{2}$, with the latter found to be a highly aggressive species. Specifically, we show that $\mathrm{I}_{2}$ causes the prompt oxidation of perovskite to form additional $\mathrm{SnI}_{4}$, as shown in Fig. 1 .

The understanding gained from these new mechanistic insights into the degradation of the Sn-based perovskite (PEA) $)_{0.2}(-$ FA) ${ }_{0.8} \mathrm{SnI}_{3}$ enables the development of mitigation strategies aimed at reducing its sensitivity towards oxidation. We find that the choice of the bottom HTM substrate can have a significant impact on perovskite film stability. We propose that dark hole withdrawal from the perovskite can cause the chemical reduction of $\mathrm{Sn}^{4+}$ species to $\mathrm{Sn}^{2+}$, which counteracts the oxidation prompted by $\mathrm{O}_{2}$ and thereby delays the formation of $\mathrm{SnI}_{4}$ and its evolution to highly aggressive $\mathrm{I}_{2}$; this ultimately leads to improved stability of the tin perovskite film. In summary, this study sheds new light upon critical features of the degradation mechanism of hybrid tin iodide perovskites, paving the way towards stable and highperformance tin-based perovskite optoelectronics.

\section{Methods}

Materials. All chemicals were purchased from Sigma-Aldrich and used as received unless stated otherwise. Likewise, solvents were acquired from Acros Organics, unless otherwise specified, and used without further purification.
$\mathbf{S n l}_{2}$ precursor purification. A $\mathrm{SnI}_{2}$ ampule (99.999\%, trace metals basis) was opened under an $\mathrm{N}_{2}$-filled glovebox. The particles of the chemical were crushed in a separate vial with a metallic spatula and placed inside a covered Petri dish, which was then put onto a hot plate and heated at $250{ }^{\circ} \mathrm{C}$ for $1 \mathrm{~h}$ to eliminate $\mathrm{SnI}_{4}$ via sublimation. After the treatment, $\mathrm{SnI}_{2}$ is kept under dark conditions in a clean vial for future use.

Substrate preparation. Glass microscope slides (VWR) were cut into $1.2 \mathrm{~cm} \times 1.2$ $\mathrm{cm}$ pieces and cleaned in an ultrasonic bath in three 10-min cycles (1: $4 \% \mathrm{v} / \mathrm{v}$ Hellmanex soap in ultrapure water; 2: acetone (VWR), 3: isopropanol (VWR)). Between every step, substrates are thoroughly rinsed with the solvent used in the previous step and then with the solvent to be used in the next step. Next, substrates are dried with a nitrogen gun and treated with UV-light/ozone for $15 \mathrm{~min}$. Substrates are then used directly for perovskite/HTM deposition. ITO substrates (Psiotec, $1.2 \mathrm{~cm} \times 1.2 \mathrm{~cm}, 15 \Omega / \mathrm{cm}^{2}$ ) were first rinsed with acetone and exposed to the same cleaning protocol. After UV/ozone, substrates were used immediately for HTM deposition. PEDOT:PSS (Heraeus Clevios GmbH) was filtered $(0.45 \mu \mathrm{m}$, PTFE) and deposited via spin-coating at $5000 \mathrm{rpm}$ for $30 \mathrm{~s}$ followed by heating at $140^{\circ} \mathrm{C}$ for $20 \mathrm{~min} .300 \mathrm{mg}$ of CuSCN were dissolved in $1 \mathrm{~mL}$ of diethyl sulphide (Sigma Aldrich) under stirring for $5 \mathrm{~h}$ and filtered $(0.45 \mu \mathrm{m}, \mathrm{PTFE})$, followed by spin-coating deposition ( $4000 \mathrm{rpm} / 40 \mathrm{~s})$ and heating $\left(60^{\circ} \mathrm{C}, 10 \mathrm{~min}\right) .248 .8 \mathrm{mg}$ of nickel acetate tetrahydrate are dissolved in $10 \mathrm{~mL}$ ethanol (VWR) and $60 \mu \mathrm{L}$ ethanolamine under stirring and heating at $65^{\circ} \mathrm{C}$ for $40 \mathrm{~min}$ and deposited via spin-coating at $4000 \mathrm{rpm} / 40 \mathrm{~s}$. Substrates are then annealed at $300^{\circ} \mathrm{C}$ for $1 \mathrm{~h}$ to obtain $\mathrm{NiO}_{\mathrm{x}}$ thin films. PMMA coatings required for some perovskite layers were obtained by dissolving $10 \mathrm{mg}$ of the polymer in $1 \mathrm{~mL}$ chlorobenzene by heating and stirring at $50{ }^{\circ} \mathrm{C}$ overnight. The solution is then applied via spin coating $(2000 \mathrm{rpm} /$ $30 \mathrm{~s})$ onto perovskite films.

Perovskite thin film preparation. Under an inert atmosphere, a 4:1 v/v mixture of DMF and DMSO (both ultradry and bottled with molecular sieves) were filtered with $0.2 \mu \mathrm{m}$ PTFE filters. Next, PEAI (GreatCell Solar), FAI (GreatCell Solar), $\mathrm{SnI}_{2}$ and $\mathrm{SnF}_{2}(99 \%)$ powders are weighed in a 0.2:0.8:1:0.1 molar ratio, respectively, to obtain $500 \mu \mathrm{L}$ of a $0.8 \mathrm{M}(\mathrm{PEA})_{0.2}(\mathrm{FA})_{0.8} \mathrm{SnI}_{3}$ perovskite precursor solution by heating and stirring at $70^{\circ} \mathrm{C}$ for $1 \mathrm{~h}$. The solutions were then filtered $(0.2 \mu \mathrm{m}$, PTFE) and deposited on the chosen substrate via a two-step spin-coating procedure (1: $1000 \mathrm{rpm} / 10 \mathrm{~s} ; 2: 5000 \mathrm{rpm} / 30 \mathrm{~s}, 800 \mu \mathrm{L}$ of ultradry toluene are dropped in the middle of the substrate after $12 \mathrm{~s}$ ), followed by $70^{\circ} \mathrm{C}$ annealing for $20 \mathrm{~min}$.

Sample characterisation. UV-Visible spectroscopy measurements were performed with a Shimadzu UV-2600 integrating-sphere spectrophotometer. Powder XRD patterns were acquired with a PANalytical X'Pert Pro MRD diffractometer by employing Ni-filtered $\mathrm{Cu}$ Ka radiation at $40 \mathrm{kV}$ and $40 \mathrm{~mA}$. Steady-state PL spectra were measured with a Jobin Ybon Horiba Fluoromax-3 spectrofluorometer. Timeresolved PL decays (time-correlated single-photon counting) were measured with a Horiba Deltaflex Modular Fluorescence Lifetime setup fitted with a PPD 900 detector. The excitation wavelength was chosen as $404 \mathrm{~nm}$ or $635 \mathrm{~nm}$ (whichever specified) and applied via a nanoLED (Model N-07; repetition rate: $1 \mathrm{MHz}$; pulse duration $<200 \mathrm{ps}$ ). XPS measurements were performed on ITO/PEDOT:PSS/ $(\mathrm{PEA})_{0.8}(\mathrm{FA})_{0.2} \mathrm{SnI}_{3}$ films using a Thermo K-Alpha ${ }^{+}$Surface Analysis setup (photon source: Al Ka, 1486.6 eV). Transport of films from the glovebox to the measuring setup was done by using a customised transfer chamber to avoid film exposure to air. Surface scans were made under ultra-high vacuum conditions with no prior etching to avoid unwanted sample reduction. Spectral fitting and deconvolution were carried out with CasaXPS software. Possible shifts in the acquired spectra were corrected by using the $\mathrm{C} 1 \mathrm{~s}$ peak at $284.8 \mathrm{eV}$. TGA measurements were conducted with a Mettler Toledo Thermogravimetric analyser under an $\mathrm{N}_{2}$ atmosphere at a $5{ }^{\circ} \mathrm{C} / \mathrm{min}$ heating rate. Perovskite film thickness $(\sim 250 \mathrm{~nm})$ was measured with an Alpha Step Tencor D500 Surface Profilometer. SEM images were taken with an LEO 1525 Field Emission Scanning Electron Microscope used at $10 \mathrm{kV}$ and fitted with an In-Lens detector. Prior to image acquisition, analysed films were unavoidably exposed to air $(\sim 1 \mathrm{~min})$ and coated with $10 \mathrm{~nm}$ of $\mathrm{Cr}$ via sputtering. ${ }^{1} \mathrm{H}-\mathrm{NMR}$ measurements were taken with a 400 $\mathrm{MHz}$ Bruker setup, using TopSpin software.

1H-NMR sample preparation. FAI, PEAI, a fresh $(\mathrm{PEA})_{0.8}(\mathrm{FA})_{0.2} \mathrm{SnI}_{3}$ film and a $(\mathrm{PEA})_{0.8}(\mathrm{FA})_{0.2} \mathrm{SnI}_{3}$ film degraded under ambient conditions for $24 \mathrm{~h}$ were dissolved separately in a DMSO (VWR)/DMSO- $\mathrm{d}_{6}$ mixture in the glovebox and then sealed into NMR tubes and taken outside for sample measurement.

$I_{2}$ detection in fully aged $(P E A)_{0.2}(F A)_{0.8} S_{3} I_{3}$ films. The detection of the halogen in toluene via UV-Visible spectroscopy in perovskite films exposed to ambient air for 3 weeks was achieved by previously coating perovskite with PMMA to capture the highly volatile halogen. We note that fully degraded samples are analysed so that $\mathrm{I}_{2}$ does not react rapidly with perovskite as soon as it forms. In consequence, only $\mathrm{SnI}_{4}$ is detected in samples analysed without PMMA coating after shorter exposure times (Supplementary Fig. 15). 
Perovskite film exposure to artificial $I_{2}$ atmospheres and characterisation. $I_{2}-$ rich atmospheres were generated by allowing $\mathrm{I}_{2}$ crystals to rest overnight in the glovebox at the bottom of closed vials initially containing $\mathrm{N}_{2}$ only, which allows $\mathrm{I}_{2}$ to achieve equilibrium vapour pressure. Taking $T=22.9^{\circ} \mathrm{C}$, we estimate the gaseous $\mathrm{I}_{2}$ content inside the vials to be $\sim 0.035 \%(\sim 350 \mathrm{ppm})^{87}$. Next, (PEA) $)_{0.2}$ $(\mathrm{FA})_{0.8} \mathrm{SnI}_{3}$ films were quickly transferred and sealed into the vials containing the $\mathrm{I}_{2}$ vapours and kept there for a period of $3 \mathrm{~min}$, after which films were removed for their characterisation. Film degradation products were extracted with $3 \mathrm{~mL}$ toluene in the glovebox (films degraded with $\mathrm{I}_{2}$ and control fresh films kept in $\mathrm{N}_{2}$ ) or in ambient air (films degraded with $\mathrm{I}_{2}$ and later exposed to ambient air and films degraded under ambient air) for UV-Visible spectroscopy measurements.

Optical degradation tests under dry/moist gas flow. In total, $1.2 \mathrm{~cm} \times 0.6 \mathrm{~cm}$ $(\mathrm{PEA})_{0.2}(\mathrm{FA})_{0.8} \mathrm{SnI}_{3}$ films were sealed inside $1 \mathrm{~cm} \times 1 \mathrm{~cm}$ quartz cuvettes with rubber covers under glovebox dry $\mathrm{N}_{2}$ environment. Cuvettes were then placed outside the glovebox and purged with constant air or $\mathrm{N}_{2}$ gas flow from cylinders. Prior to reaching the sample, gas is bubbled through water/glycerol solutions to control humidity (relative humidity in gas flow determined by water/glycerol ratio, as specified elsewhere ${ }^{88}$ ). Simultaneously, optical degradation of perovskite is tracked by measuring the absorbance of the sealed film every $5 \mathrm{~min}$ for a $30 \mathrm{~min}$ period.

Device fabrication. PEDOT:PSS is deposited on ITO substrates as specified above and transferred to an $\mathrm{N}_{2}$-filled glovebox. A (PEA) $0_{0.8}(\mathrm{FA})_{0.2} \mathrm{SnI}_{3}$ perovskite solution $(0.8 \mathrm{M})$ made with 9:1 v/v DMF:DMSO is stirred for $1 \mathrm{~h}$ at $70^{\circ} \mathrm{C}$ and filtered $(0.2$ $\mu \mathrm{m}$, PTFE) before film deposition. The solution is applied onto PEDOT:PSS via spin-coating at $4000 \mathrm{rpm}$ for $20 \mathrm{~s}$. Diethyl ether is used as the antisolvent $(500 \mu \mathrm{L}$ applied at the tenth second), followed by annealing at $70^{\circ} \mathrm{C}$ for $20 \mathrm{~min}$. Next, a $30 \mathrm{mg} / \mathrm{mL} \mathrm{PC}_{60} \mathrm{BM}$ (Ossila) solution in chlorobenzene is deposited at $2000 \mathrm{rpm}$ for 20 s. Next, a bathocuproine (BCP) solution in isopropanol $(0.5 \mathrm{mg} / \mathrm{mL})$ is used to coat $\mathrm{PC}_{60} \mathrm{BM}$ at $5000 \mathrm{rpm}$ for $20 \mathrm{~s}$. Hundred nanometre-thick $\mathrm{Ag}$ electrodes are then processed via vacuum $\left(10^{-6} \mathrm{mbar}\right)$ thermal evaporation by using a mask leading to a $0.045 \mathrm{~cm}^{2}$ device active area.

Device characterisation. J-V characteristics were measured immediately after fabrication by using simulated AM1.5 solar light (Oriel Instruments) and a Keithley 2400 source metre at a scan rate of $50 \mathrm{mV} / \mathrm{s}$ in forwarding bias. Light intensity calibration was carried out with a silicon photodiode. Devices were kept under inert conditions during the measurements by loading them in the glovebox in a homemade measuring chamber.

Computational details. We carried out $\mathrm{DFT}^{89}$ calculations as implemented in the Quantum ESPRESSO package ${ }^{90,91}$. For the reaction energies, the Kohn-Sham wave-functions and energies are calculated with the GGA-PBEsol ${ }^{92}$ for electron exchange and correlation, using a plane-wave basis, with energy and charge density cutoffs of 50 and $500 \mathrm{Ry}$, respectively. Ultrasoft pseudopotentials ${ }^{93}$ are used to describe the core-valence interactions. The structural relaxation is performed until the force on each atom is smaller than $0.01 \mathrm{eV} / \AA$. The Brillouin zone integration was sampled following the Monkhorst-Pack scheme ${ }^{94}$ and convergence with respect to the k-points grid was tested for each compound. For FASnI ${ }_{3}$, we have used a supercell of 96 atoms to allow for more degrees of freedom for a lowsymmetry structure.

The reactions energies, $E_{R}$, are calculated as the sum of total energies, $E_{T o t}$, of the product minus the sum of total energies of the reactants $\left(E_{R}=\right.$

$\left.n_{i} \Sigma_{\text {products }}\left(E_{T o t}(i)\right)-n_{i} \Sigma_{\text {reactants }}\left(E_{\text {Tot }}(i)\right)\right)$, where $n_{i}$ and $E_{\text {tot }}$ are the numbers and the total energy of the compounds and chemical species involved in the reaction. For example, the energy of reaction (1) is calculated as:

$$
E_{R}(1)=\left[E_{T o t}\left(\mathrm{SnI}_{4}\right)+E_{T o t}\left(\mathrm{SnO}_{2}\right)+2 E_{T o t}(\mathrm{AI})\right]-\left[2 E_{\text {Tot }}\left(\mathrm{ASnI}_{3}\right)+E_{T o t}\left(\mathrm{O}_{2}\right)\right] .
$$

In order to take into account the contribution of the zero-point energy and the entropy effects to the reaction energies, we have calculated the Gibbs free energy $\left(E_{T o t}=G(T)=E_{L}+E_{0}+E_{T}-\right.$ TS) for each reaction component at the PBE level within the harmonic approximation at $300 \mathrm{~K}$ as implemented in the CRYSTAL17 code ${ }^{95-98}$. Here $E_{L}$ is the electronic energy corresponding to the DFT total energy at $0 \mathrm{~K}, E_{0}$ is the zero-point energy, $E_{T}$ is the thermal contribution to the vibrational energy and TS is the entropy contribution. Effective core pseudopotentials were adopted for the heavy atoms Sn (Sn_ECP28MDF-411(51d)G), and I

(I_POB_TZVP_2018) and all-electron Gaussian basis sets for N (N_pob_TZVP_2012), C (C_pob_TZVP_2012), H (H_pob_TZVP_2012) and O (O_8-411d11G_valenzano_2006) atoms. These basis sets are taken from the online library of the CRYSTAL17 code ${ }^{95,96}$. For the periodic systems we have used a $2 \times$ $2 \times 2$ supercell for $\mathrm{SnI}_{4}(320$ atoms) and FAI salt $(288$ atoms), $3 \times 3 \times 3$ supercells for $\mathrm{FASnI}_{3}$ (324 atoms), and a $4 \times 4 \times 4$ supercell for $\mathrm{SnO}_{2}$ (384). We note that the calculated reaction energies with DFT at $0 \mathrm{~K}$ are $-4.67 \mathrm{eV},-0.09 \mathrm{eV}$, and $0.67 \mathrm{eV}$ for reactions (1), (2), and (5), respectively, which yields similar trends as with the harmonic approximation. We also note that we have used the $\mathrm{FASnI}_{3}$ system for the calculation of the energetics of Reaction (1), instead of the stoichiometric compound $\mathrm{PEA}_{0.2} \mathrm{FA}_{0.8} \mathrm{SnI}_{3}$ studied in our experiments due to the lack of a welldefined crystal structure from XRD.
For surface calculations, we have cut the $\mathrm{FASnI}_{3}$ supercell structure along the crystalline plane (001) with $\mathrm{Sn} / \mathrm{I}$ and FA/I terminations. The resulting slabs have symmetrically equivalent terminations to avoid large dipole effects. To maintain the bulk electronic properties, the slab thickness is chosen to be three times the above supercell of the bulk structure in the out-of-plane direction. To avoid the interaction between the repeated images, the out-of-plane direction of the box containing the slab and the vacuum layer was fixed to $50 \AA$. The slab without molecules was, first, fully relaxed using the generalised gradient approximation (GGA) with Perdew-Burke-Ernzerhof (PBE) formalism ${ }^{99}$ for the exchangecorrelation. The van der Waals corrections were accounted for using the Grimme dispersion correction DFT-D3 ${ }^{100}$. As above, ultrasoft pseudopotentials were used for describing the core-valence interactions. The energy and charge density cutoffs were set to $40 \mathrm{Ry}$ and $400 \mathrm{Ry}$, respectively. The Brillouin zone integration was sampled with a $4 \times 4 \times 1 k$-points grid. Dipole corrections were accounted for to eliminate dipole-dipole interactions between image supercells. For the adsorption of $\mathrm{O}_{2}$ or $\mathrm{I}_{2}$ molecules, we have considered three different configurations of the molecules on the $\mathrm{FASnI}_{3}$ surface, then letting them fully relax. In the case of $\mathrm{Sn} / \mathrm{I}$ termination, the molecules were initially positioned at distances of $4.5 \AA$ from the $\mathrm{SnI}_{2}$ surface on top of (a) I atom, (b) Sn atom, and (c) FA cation as shown in Supplementary Fig. 18. In the case of FA/I termination, two configurations were considered on top of (a) FA cation and (b) I atom, as shown in Supplementary Fig. 21. The final structures after relaxations are shown in Supplementary Figs. 19 and 20 for $\mathrm{O}_{2}$ and $\mathrm{I}_{2}$, respectively. To further examine the sensitivity of the optimised distance between the $\mathrm{O}_{2}$ molecules and the surface to the initial position before relaxation when the $\mathrm{O}_{2}$ are placed on top of FA and I (Supplementary Fig. 18a, c), we have manually placed the molecules closer to the surface than the optimised distance. After subsequent relaxation, the molecules were repelled to the optimised positions of the initial relaxation; this indicates that there is no bonding interaction between the $\mathrm{O}_{2}$ molecule and the FA or I at the surface.

Reporting summary. Further information on experimental design is available in the Nature Research Reporting Summary linked to this paper.

\section{Data availability}

The data and computational methods that support the findings of this manuscript are available from the corresponding authors upon reasonable request.

\section{Code availability}

The CRYSTAL and Quantum Espresso codes that were used are well established computational materials science codes. Quantum Espresso is a General Public Licensed programme and freely accessible and CRYSTAL is distributed according to specific license terms that are available from the developers.

Received: 10 July 2020; Accepted: 30 March 2021; Published online: 14 May 2021

\section{References}

1. Kojima, A., Teshima, K., Shirai, Y. \& Miyasaka, T. Organometal halide perovskites as visible-light sensitizers for photovoltaic cells. J. Am. Chem. Soc. 131, 6050-6051 (2009).

2. NREL Best Research-Cell Efficiency Chart. https://www.nrel.gov/pv/cellefficiency.html (2021).

3. Stranks, S. D. et al. Electron-hole diffusion lengths exceeding 1 micrometer in an organometal trihalide perovskite absorber. Science 342, 341-344 (2013).

4. Xing, G. et al. Long-range balanced electron- and hole-transport lengths in organic-inorganic $\mathrm{CH}_{3} \mathrm{NH}_{3} \mathrm{PbI}_{3}$. Science 342, 344-347 (2013).

5. Adinolfi, V. et al. The in-gap electronic state spectrum of methylammonium lead iodide single-crystal perovskites. Adv. Mater. 28, 3406-3410 (2016).

6. Yin, W. et al. Unusual defect physics in $\mathrm{CH}_{3} \mathrm{NH}_{3} \mathrm{PbI}_{3}$ perovskite solar cell absorber. Appl. Phys. Lett. 104, 063903 (2014).

7. Snaith, H. J. Present status and future prospects of perovskite photovoltaics. Nat. Mater. 17, 372-376 (2018).

8. Correa-Baena, J. P. et al. The rapid evolution of highly efficient perovskite solar cells. Energy Environ. Sci. 10, 710-727 (2017).

9. Jena, A. K., Kulkarni, A. \& Miyasaka, T. Halide perovskite photovoltaics: background, status, and future prospects. Chem. Rev. 119, 3036-3103 (2019).

10. Noel, N. K. et al. Lead-free organic-inorganic tin halide perovskites for photovoltaic applications. Energy Environ. Sci. 7, 3061-3068 (2014).

11. Hao, F., Stoumpos, C. C., Cao, D. H., Chang, R. P. H. \& Kanatzidis, M. G. Lead-free solid-state organic-inorganic halide perovskite solar cells. Nat. Photon. 8, 489-494 (2014).

12. Stoumpos, C. C. et al. Hybrid germanium iodide perovskite semiconductors: active lone pairs, structural distortions, direct and indirect energy gaps, and strong nonlinear optical properties. J. Am. Chem. Soc. 137, 6804-6819 (2015). 
13. Krishnamoorthy, T. et al. Lead-free germanium iodide perovskite materials for photovoltaic applications. J. Mater. Chem. A 3, 23829-23832 (2015).

14. Park, B.-W. et al. Bismuth based hybrid perovskites $\mathrm{A}_{3} \mathrm{Bi}_{2} \mathrm{I}_{9}$ (A: methylammonium or cesium) for solar cell application. Adv. Mater. 27, 6806-6813 (2015).

15. Hebig, J. C., Kühn, I., Flohre, J. \& Kirchartz, T. Optoelectronic properties of $\left(\mathrm{CH}_{3} \mathrm{NH}_{3}\right)_{3} \mathrm{Sb}_{2} \mathrm{I}_{9}$ thin films for photovoltaic applications. ACS Energy Lett. 1, 309-314 (2016).

16. Konstantakou, M. \& Stergiopoulos, T. A critical review on tin halide perovskite solar cells. J. Mater. Chem. A 5, 11518-11549 (2017).

17. Lee, S. J. et al. Reducing carrier density in formamidinium tin perovskites and its beneficial effects on stability and efficiency of perovskite solar cells. ACS Energy Lett. 3, 46-53 (2018).

18. Jokar, E. et al. Slow surface passivation and crystal relaxation with additives to improve device performance and durability for tin-based perovskite solar cells. Energy Environ. Sci. 11, 2353-2362 (2018).

19. Gao, W. et al. Robust stability of efficient lead-free formamidinium tin iodide perovskite solar cells realized by structural regulation. J. Phys. Chem. Lett. 9, 6999-7006 (2018)

20. Jokar, E., Chien, C.-H., Tsai, C.-M., Fathi, A. \& Diau, E. W.-G. Robust tinbased perovskite solar cells with hybrid organic cations to attain efficiency approaching 10\%. Adv. Mater. 31, 1804835 (2018).

21. Diau, E. W. G., Jokar, E. \& Rameez, M. Strategies to improve performance and stability for tin-based perovskite solar cells. ACS Energy Lett. 4, 1930-1937 (2019).

22. Nasti, G. \& Abate, A. Tin halide perovskite $\left(\mathrm{ASnX}_{3}\right)$ solar cells: a comprehensive guide toward the highest power conversion efficiency. Adv. Energy Mater. 10, 1902467 (2019).

23. Liu, G. et al. Regulated crystallization of efficient and stable tin-based perovskite solar cells via a self-sealing polymer. ACS Appl. Mater. Interfaces 12, 14049-14056 (2020).

24. Liu, X. et al. Templated growth of $\mathrm{FASnI}_{3}$ crystals for efficient tin perovskite solar cells. Energy Environ. Sci. 13, 2896-2902 (2020).

25. Wang, C. et al. Self-repairing tin-based perovskite solar cells with a breakthrough efficiency over 11\%. Adv. Mater. 32, 1907623 (2020).

26. Nakamura, T. et al. Sn(IV)-free tin perovskite films realized by in situ $\mathrm{Sn}(0)$ nanoparticle treatment of the precursor solution. Nat. Commun. 11, 3008 (2020).

27. Wang, T. et al. Highly air-stable tin-based perovskite solar cells through grainsurface protection by gallic acid. ACS Energy Lett. 5, 1741-1749 (2020).

28. Liu, X. et al. Efficient and stable tin perovskite solar cells enabled by amorphous-polycrystalline structure. Nat. Commun. 11, 2678 (2020).

29. He, X. et al. Highly efficient tin perovskite solar cells achieved in a wide oxygen concentration range. J. Mater. Chem. A 8, 2760-2768 (2020).

30. Li, J. et al. Biological impact of lead from halide perovskites reveals the risk of introducing a safe threshold. Nat. Commun. 11, 310 (2020).

31. Stoumpos, C. C., Malliakas, C. D. \& Kanatzidis, M. G. Semiconducting tin and lead iodide perovskites with organic cations: phase transitions, high mobilities, and near-infrared photoluminescent properties. Inorg. Chem. 52, 9019-9038 (2013).

32. Herz, L. M. Charge-carrier mobilities in metal halide perovskites: fundamental mechanisms and limits. ACS Energy Lett. 2, 1539-1548 (2017).

33. Nishimura, K. et al. Lead-free tin-halide perovskite solar cells with $13 \%$ efficiency. Nano Energy 74, 104858 (2020).

34. Takahashi, Y., Hasegawa, H., Takahashi, Y. \& Inabe, T. Hall mobility in tin iodide perovskite $\mathrm{CH}_{3} \mathrm{NH}_{3} \mathrm{SnI}_{3}$ : Evidence for a doped semiconductor. J. Solid State Chem. 205, 39-43 (2013).

35. Johnston, M. B. \& Herz, L. M. Hybrid perovskites for photovoltaics: chargecarrier recombination, diffusion, and radiative efficiencies. Acc. Chem. Res. 49, 146-154 (2016).

36. Kumar, M. H. et al. Lead-free halide perovskite solar cells with high photocurrents realized through vacancy modulation. Adv. Mater. 26, 7122-7127 (2014).

37. Marshall, K. P., Walker, M., Walton, R. I. \& Hatton, R. A. Enhanced stability and efficiency in hole-transport-layer-free $\mathrm{CsSnI}_{3}$ perovskite photovoltaics. Nat. Energy 1, 16178 (2016).

38. Lanzetta, L., Marin-Beloqui, J. M., Sanchez-Molina, I., Ding, D. \& Haque, S. A. Two-dimensional organic tin halide perovskites with tunable visible emission and their use in light-emitting devices. ACS Energy Lett. 2, 1662-1668 (2017).

39. Liao, Y. et al. Highly oriented low-dimensional tin halide perovskites with enhanced stability and photovoltaic performance. J. Am. Chem. Soc. 139, 6693-6699 (2017).

40. Cao, D. H. et al. Thin films and solar cells based on semiconducting twodimensional Ruddlesden-Popper $\left(\mathrm{CH}_{3}\left(\mathrm{CH}_{2}\right)_{3} \mathrm{NH}_{3}\right)_{2}\left(\mathrm{CH}_{3} \mathrm{NH}_{3}\right)_{\mathrm{n}-1} \mathrm{Sn}_{\mathrm{n}} \mathrm{I}_{3 \mathrm{n}+1}$ perovskites. ACS Energy Lett. 2, 982-990 (2017).

41. Shao, S. et al. Highly reproducible sn-based hybrid perovskite solar cells with 9\% efficiency. Adv. Energy Mater. 8, 1702019 (2017).

42. Wang, F. et al. 2D-quasi-2D-3D hierarchy structure for tin perovskite solar cells with enhanced efficiency and stability. Joule 2, 2732-2743 (2018).
43. Li, M. et al. Tin halide perovskite films made of highly oriented $2 \mathrm{D}$ crystals enable more efficient and stable lead-free perovskite solar cells. ACS Energy Lett. 5, 1923-1929 (2020)

44. Jiang, X. et al. Ultra-high open-circuit voltage of tin perovskite solar cells via an electron transporting layer design. Nat. Commun. 11, 1245 (2020).

45. Chen, M. et al. High-performance lead-free solar cells based on tin-halide perovskite thin films functionalized by a divalent organic cation. ACS Energy Lett. 5, 2223-2230 (2020).

46. Ran, C. et al. Conjugated organic cations enable efficient self-healing $\mathrm{FASnI}_{3}$ solar cells. Joule 3, 3072-3087 (2019).

47. Aristidou, N. et al. The role of oxygen in the degradation of methylammonium lead trihalide perovskite photoactive layers. Angew. Chem. Int. Ed. 54, 8208-8212 (2015).

48. Bryant, D. et al. Light and oxygen induced degradation limits the operational stability of methylammonium lead triiodide perovskite solar cells. Energy Environ. Sci. 9, 1655-1660 (2016).

49. Aristidou, N. et al. Fast oxygen diffusion and iodide defects mediate oxygeninduced degradation of perovskite solar cells. Nat. Commun. 8, 15218 (2017).

50. Aristidou, N., Eames, C., Islam, M. S. \& Haque, S. A. Insights into the increased degradation rate of $\mathrm{CH}_{3} \mathrm{NH}_{3} \mathrm{PbI}_{3}$ solar cells in combined water and $\mathrm{O}_{2}$ environments. J. Mater. Chem. A 5, 25469-25475 (2017).

51. Bu, X. et al. Surface passivation of perovskite films via iodide salt coatings for enhanced stability of organic lead halide perovskite solar cells. Sol. RRL 3 , 1800282 (2018)

52. Lanzetta, L., Aristidou, N. \& Haque, S. A. Stability of lead and tin halide perovskites: the link between defects and degradation. J. Phys. Chem. Lett. 11, 574-585 (2020).

53. Zhang, Y. et al. Ambient fabrication of organic-inorganic hybrid perovskite solar cells. Small Methods 5, 2000744 (2020).

54. Rahim, W. et al. Geometric analysis and formability of the cubic $\mathrm{A}_{2} \mathrm{BX}_{6}$ vacancyordered double perovskite structure. Chem. Mater. 32, 9573-9583 (2020).

55. Qiu, X. et al. From unstable $\mathrm{CsSnI}_{3}$ to air-stable $\mathrm{Cs}_{2} \mathrm{SnI}_{6}$ : a lead-free perovskite solar cell light absorber with bandgap of $1.48 \mathrm{eV}$ and high absorption coefficient. Sol. Energy Mater. Sol. Cells 159, 227-234 (2017).

56. Ke, W., Stoumpos, C. C. \& Kanatzidis, M. G. "Unleaded" perovskites: status quo and future prospects of tin-based perovskite solar cells. Adv. Mater. 31, 1803230 (2018).

57. Kubicki, D. J. et al. Local structure and dynamics in methylammonium, formamidinium, and cesium Tin(II) mixed-halide perovskites from ${ }^{119} \mathrm{Sn}$ Solid-state NMR. J. Am. Chem. Soc. 142, 7813-7826 (2020).

58. Leijtens, T., Prasanna, R., Gold-Parker, A., Toney, M. F. \& McGehee, M. D. Mechanism of tin oxidation and stabilization by lead substitution in tin halide perovskites. ACS Energy Lett. 2, 2159-2165 (2017).

59. Liang, $\mathrm{H}$. et al. High color purity lead-free perovskite light-emitting diodes via Sn stabilization. Adv. Sci. 7, 1903213 (2020).

60. Moeller, T., Edwards, D. C., Brandt, R. L. \& Kleinberg, J. Tin (IV) iodide. Inorg. Synth. 4, 119-121 (1953).

61. Hickling, G. G. Gravimetric analysis-the synthesis of tin iodide. J. Chem. Educ. 67, 702-703 (1990).

62. Sundqvist, J., Ottosson, M. \& Hårsta, A. CVD of epitaxial $\mathrm{SnO}_{2}$ films by the $\mathrm{SnI}_{4} / \mathrm{O}_{2}$ precursor combination. Chem. Vap. Depos. 10, 77-82 (2004).

63. Babayigit, A. et al. Assessing the toxicity of $\mathrm{Pb}$-and $\mathrm{Sn}$-based perovskite solar cells in model organism Danio rerio. Sci. Rep. 6, 18721 (2016).

64. Ke, J. C. R. et al. Ambient-air-stable inorganic $\mathrm{Cs}_{2} \mathrm{SnI}_{6}$ double perovskite thin films via aerosol-assisted chemical vapour deposition. J. Mater. Chem. A 6 , 11205-11214 (2018)

65. Zhu, W. et al. Deciphering the degradation mechanism of the lead-free all inorganic perovskite $\mathrm{Cs}_{2} \mathrm{SnI}_{6}$. npj Mater. Degrad. 3, 7 (2019).

66. Zibouche, N. \& Islam, M. S. Structure-electronic property relationships of 2D Ruddlesden-Popper tin- and lead-based iodide perovskites. ACS Appl. Mater. Interfaces 12, 15328-15337 (2020).

67. Wang, Z., Ganose, A. M., Niu, C. \& Scanlon, D. O. First-principles insights into tin-based two-dimensional hybrid halide perovskites for photovoltaics. J. Mater. Chem. A 6, 5652-5660 (2018).

68. Haruyama, J., Sodeyama, K., Han, L. \& Tateyama, Y. Surface properties of $\mathrm{CH}_{3} \mathrm{NH}_{3} \mathrm{PbI}_{3}$ for perovskite solar cells. Acc. Chem. Res. 49, 554-561 (2016).

69. Quarti, C., De Angelis, F. \& Beljonne, D. Influence of surface termination on the energy level alignment at the $\mathrm{CH}_{3} \mathrm{NH}_{3} \mathrm{PbI}_{3}$ perovskite/ $\mathrm{C}_{60}$ interface. Chem. Mater. 29, 958-968 (2017).

70. Huang, S., Wu, X., Niu, J. \& Qin, S. Structural, magnetic and electronic properties of $\mathrm{CrO}_{2}$ at multimegabar pressures. RSC Adv. 8, 24561-24570 (2018).

71. El Ajjouri, Y. et al. Mechanochemical synthesis of Sn(II) and Sn(IV) iodide perovskites and study of their structural, chemical, thermal, optical, and electrical properties. Energy Technol. 8, 1900788 (2019).

72. Funabiki, F., Toda, Y. \& Hosono, H. Optical and electrical properties of perovskite variant $\left(\mathrm{CH}_{3} \mathrm{NH}_{3}\right)_{2} \mathrm{SnI}_{6}$. J. Phys. Chem. C 122, 10749-10754 (2018). 
73. Bian, Z. et al. Improving performance of lead-free formamidinium tin triiodide perovskite solar cells by tin source purification. Sol. RRL 2, 1800136 (2018).

74. Rath, T. et al. Photovoltaic properties of a triple cation methylammonium/ formamidinium/phenylethylammonium tin iodide perovskite. J. Mater. Chem. A 7, 9523-9529 (2019).

75. Zhu, Z., Chueh, C. C., Li, N., Mao, C. \& Jen, A. K. Y. Realizing efficient leadfree formamidinium tin triiodide perovskite solar cells via a sequential deposition route. Adv. Mater. 30, 1703800 (2017).

76. Yang, Z. et al. Enhancing electron diffusion length in narrow-bandgap perovskites for efficient monolithic perovskite tandem solar cells. Nat. Commun. 10, 4498 (2019).

77. Parrott, E. S. et al. Effect of structural phase transition on charge-carrier lifetimes and defects in $\mathrm{CH}_{3} \mathrm{NH}_{3} \mathrm{SnI}_{3}$ perovskite. J. Phys. Chem. Lett. 7, 1321-1326 (2016).

78. Gamsjäger, H., Gajda, T., Sangster, J., Saxena, S. K. \& Voigt, W. Chemical Thermodynamics Vol.12-Chemical Thermodynamics of Tin. (eds Perrone, J.) (Nuclear Energy Agency of the OECD, Issy-les-Molineaux, France, 2012).

79. Atkins, P. \& De Paula, J. Atkins' Physical Chemistry 8th edn (Oxford University Press, Oxford, United Kingdom, 2006).

80. Frost, J. M. et al. Atomistic origins of high-performance in hybrid halide perovskite solar cells. Nano Lett. 14, 2584-2590 (2014).

81. Yang, J., Siempelkamp, B. D., Liu, D. \& Kelly, T. L. Investigation of $\mathrm{CH}_{3} \mathrm{NH}_{3} \mathrm{PbI}_{3}$ degradation rates and mechanisms in controlled humidity environments using in situ techniques. ACS Nano 9, 1955-1963 (2015).

82. Niu, G., Guo, X. \& Wang, L. Review of recent progress in chemical stability of perovskite solar cells. J. Mater. Chem. A 3, 8970-8980 (2015).

83. Tyagi, D., Varma, S. \& Bharadwaj, S. R. Pt/zirconia catalyst for hydrogen generation from $\mathrm{HI}$ decomposition reaction of S-I cycle. Int. J. Energy Res. 39 484-493 (2015).

84. Zhang, Y. et al. HI decomposition over carbon-based and Ni-impregnated catalysts of the sulfur-iodine cycle for hydrogen production. Ind. Eng. Chem. Res. 54, 1498-1504 (2015).

85. Singhania, A. \& Bhaskarwar, A. N. Development of catalysts for hydrogen production from hydrogen iodide decomposition in thermo-chemical watersplitting sulfur-iodine cycle: a review. Catal. Rev.-Sci. Eng. 59, 446-489 (2017).

86. Cao, J. et al. Enhanced performance of tin-based perovskite solar cells induced by an ammonium hypophosphite additive. J. Mater. Chem. A 7, 26580-26585 (2019).

87. Leenson, I. A. Sublimation of iodine at various pressures. Multipurpose experiments in inorganic and physical chemistry. J. Chem. Educ. 82, 241-245 (2005).

88. Forney, C. F. \& Brandl, D. G. Control of humidity in small controlledenvironment chambers using glycerol-water solutions. Horttechnology 2, 52-54 (1992)

89. Kohn, W. \& Sham, L. J. Self-consistent equations including exchange and correlation effects. Phys. Rev. 140, A1133-A1138 (1965).

90. Giannozzi, P. et al. Advanced capabilities for materials modelling with quantum ESPRESSO. J. Phys. Condens. Matter 29, 465901 (2017).

91. Giannozzi, P. et al. Quantum espresso: a modular and open-source software project for quantum simulations of materials. J. Phys. Condens. Matter 21, 395502 (2009).

92. Perdew, J. P. et al. Restoring the density-gradient expansion for exchange in solids and surfaces. Phys. Rev. Lett. 100, 136406 (2008).

93. Vanderbilt, D. Soft self-consistent pseudopotentials in a generalized eigenvalue formalism. Phys. Rev. B 41, 7892-7895 (1990).

94. Monkhorst, H. J. \& Pack, J. D. Special points for Brillouin-zone integrations. Phys. Rev. B 13, 5188-5192 (1976).

95. Dovesi, R. et al. Quantum-mechanical condensed matter simulations with CRYSTAL. WIREs Comput. Mol. Sci. 8, e1360 (2018).

96. R. Dovesi et al. CRYSTAL17 User's Manual (University of Torino, Torino, 2017).

97. Pascale, F. et al. The calculation of the vibrational frequencies of crystalline compounds and its implementation in the CRYSTAL code. J. Comput. Chem. 25, 888-897 (2004)

98. Zicovich-Wilson, C. M. et al. Calculation of the vibration frequencies of $a-$ quartz: the effect of hamiltonian and basis set. J. Comput. Chem. 25, 1873-1881 (2004).

99. Perdew, J. P., Burke, K. \& Ernzerhof, M. Generalized gradient approximation made simple. Phys. Rev. Lett. 77, 3865-3868 (1996).
100. Grimme, S., Antony, J., Ehrlich, S. \& Krieg, H. A consistent and accurate ab initio parametrization of density functional dispersion correction (DFT-D) for the 94 elements H-Pu. J. Chem. Phys. 132, 154104 (2010).

\section{Acknowledgements}

S.A.H. acknowledges support from EPSRC (grant numbers EP/R020574/1, EP/R023581/ 1 and EP/P032591/1). L.L. was supported by the EPSRC Centre for Doctoral Training in Plastic Electronics (grant number EP/L016702/1). M.S.I. and N.Z. gratefully acknowledge the EPSRC Grant "Towards Self-scrubbing Stable and Scalable Perovskite Solar Cells" (EP/R020485/1). For supercomputer resources, we thank the MCC/Archer consortium (EP/L000202/1) and Isambard UK National Tier-2 HPC Service operated by GW4 and the UK Met Office and funded by EPSRC (EP/P020224/1).

\section{Author contributions}

S.A.H. designed and supervised the experimental project. M.S.I. and N.Z. designed and performed the computational work. L.L. designed experiments, performed sample preparation, spectroscopy and XRD measurements, solar cell fabrication and characterisation, TGA and took photographs of the experimental setup. T.W. carried out sample preparation, spectroscopy measurements, solar cell fabrication and characterisation, TGA and took photographs of the experimental setup. X.L. conducted sample preparation, spectroscopy and XRD measurements and solar cell fabrication and characterisation. D.D. contributed to solar cell fabrication. G.M. performed sample preparation, optical spectroscopy and microscopy measurements and took photographs of the experimental setup. R.J.E.W. contributed to optical spectroscopy measurements and analysis. B.G. provided assistance in optical degradation measurements. T.J.M. conducted solar cell fabrication and characterisation, sample preparation and spectroscopy measurements. T.J.M would like to thank the Royal Commission for the Exhibition of 1851 for their financial support through an 1851 Research Fellowship. L.L., S.A.H., N Z. and M.S.I. drafted the initial version of the manuscript. All authors contributed to the analysis, discussion and preparation of the final version of the paper.

\section{Competing interests}

The authors declare no competing interests.

\section{Additional information}

Supplementary information The online version contains supplementary material available at https://doi.org/10.1038/s41467-021-22864-z.

Correspondence and requests for materials should be addressed to M.S.I. or S.A.H.

Peer review information Nature Communications thanks the anonymous reviewer(s) for their contribution to the peer review of this work.

Reprints and permission information is available at http://www.nature.com/reprints

Publisher's note Springer Nature remains neutral with regard to jurisdictional claims in published maps and institutional affiliations.

Open Access This article is licensed under a Creative Commons Attribution 4.0 International License, which permits use, sharing, adaptation, distribution and reproduction in any medium or format, as long as you give appropriate credit to the original author(s) and the source, provide a link to the Creative Commons license, and indicate if changes were made. The images or other third party material in this article are included in the article's Creative Commons license, unless indicated otherwise in a credit line to the material. If material is not included in the article's Creative Commons license and your intended use is not permitted by statutory regulation or exceeds the permitted use, you will need to obtain permission directly from the copyright holder. To view a copy of this license, visit http://creativecommons.org/ licenses/by/4.0/.

(C) The Author(s) 2021 